\title{
Chinese Guanxi: An Integrative Review and New Directions for Future Research
}

\section{Chao G. Ghen, ${ }^{1,2}$ Xiao-Ping Chen, ${ }^{3}$ and Shengsheng Huang ${ }^{4}$}

${ }^{1}$ Rutgers, the State University of New Jersey, USA, ${ }^{2}$ Nanjing University, China, ${ }^{3}$ University of Washington, USA, and ${ }^{4}$ University of Houston-Victoria, USA

ABSTRACT In this article we review research on Chinese guanxi and social networking in the past twenty years and identify the major perspectives, theories, and methodologies used in guanxi research at micro and macro levels. We summarize the main findings of over 200 journal articles on guanxi research in terms of its conceptual definitions and measurements, its antecedents and consequences, and its dynamics and processes. Furthermore, we identify the gaps between different levels of guanxi research and discuss future directions to advance our understanding of the complex and intricate guanxi phenomenon.

KEYwords Chinese culture, guanxi ethics, guanxi, social capital, social networking

中国人的关系: 综合文献回顾及未来研究方向

\section{摘要}

本文综合回顾了过去二十年来中外文献中有关中国人关系和社会网络的研究，对微观及宏观 层次上关系研究的主要视角、理论、及研究方法进行了区分, 并对关系研究在概念定义、测 電、前因后果、动态变化和过程等方面的主要实证研究结果进行了总结。此外, 本文论述了 不同㫳次关系研究之间的空白并指出了未来研究方向， 以便更深入全面地探讨和了解关系现象的错综复杂性。

关键词：人际关系, 关系伦理, 社会资本, 社会网络, 中国文化 


\section{INTRODUGTION}

Recently, Management and Organization Review published a meta-analytic study (Luo, Huang, \& Wang, 2012) focusing on the statistical relationship in 53 studies between two types of guanxi ties (business and government) at the firm level and firm performance (both economic and operational). However, the guanxi literature is much wider than these 53 quantitative studies. Research on guanxi is also the earliest and the most important contribution to the mainstream management literature (Jia, You, \& Du, 2012). A comprehensive review, that covers the literature of Chinese guanxi and social networking more widely, including both qualitative and quantitative research, micro and macro levels, crossing multiple disciplines, and incorporating articles published in both English and Chinese language journals, is long overdue. The current article aims to fill this void and to identify directions for future research.

To find relevant articles, we started our search with the 'Business Source Premier' database. The terms 'guanxi', 'social capital, China', 'social network, China', 'managerial ties, China', and 'personal relationship, China' were used to search the keywords, titles, and abstracts of scholarly studies in peer-reviewed academic journals in the past twenty years. This search resulted in 235 articles. The abstracts of these initial publications were reviewed to determine whether the papers indeed treat guanxi as a major construct. Of these articles, 180 were selected. To this pool we added some thirty guanxi related articles published in four well-established Chinese language academic journals, including Indigenous Psychological Research (本土心理学 研究), Management World (管理世界), Chinese Social Sciences (中国社会科学), and Sociological Studies (社会学研究). Figure 1 shows the distribution of journal publications of guanxi per year between 1990 and 2010. It can be seen that the number of publications increased rapidly from 1990 and peaked in 2008.

A quick glance at this research suggests three distinct streams. One stream focuses on the individual/interpersonal level and studies the domains of guanxi, the measurement of guanxi, the antecedents and outcomes of guanxi, or the factors that influence the quality of guanxi (e.g., Chen \& Chen, 2004; Chen, Friedman, Yu, Fang, \& Lu, 2009; Chen \& Peng, 2008; Tsui \& Farh, 1997). Another stream studies organizational level guanxi such as firm-to-firm and firm-to-government guanxi, with a main focus on its effects on firm performance or other financial outcomes (e.g., Luo, 2003; Park \& Luo, 2001; Peng \& Luo, 2000; Tsang, 1998; Xin \& Pearce, 1996). The third newly emerging stream is concerned with the social and moral dilemmas of guanxi, focusing mainly on how guanxi practices for the benefit of focal units may affect the super-ordinate units in which the subunit is embedded (e.g., Chen \& Chen, 2009; Dunfee \& Warren, 2001) and on the tensions between traditional relational ethics as opposed to modernist professional ethics (e.g., Ho \& Redfern, 2010; Su, Sirgy, \& Littlefield, 2003; Tan \& Snell, 2002). 
Figure 1. The number of guanxi papers published in journals from 1990 to 2010

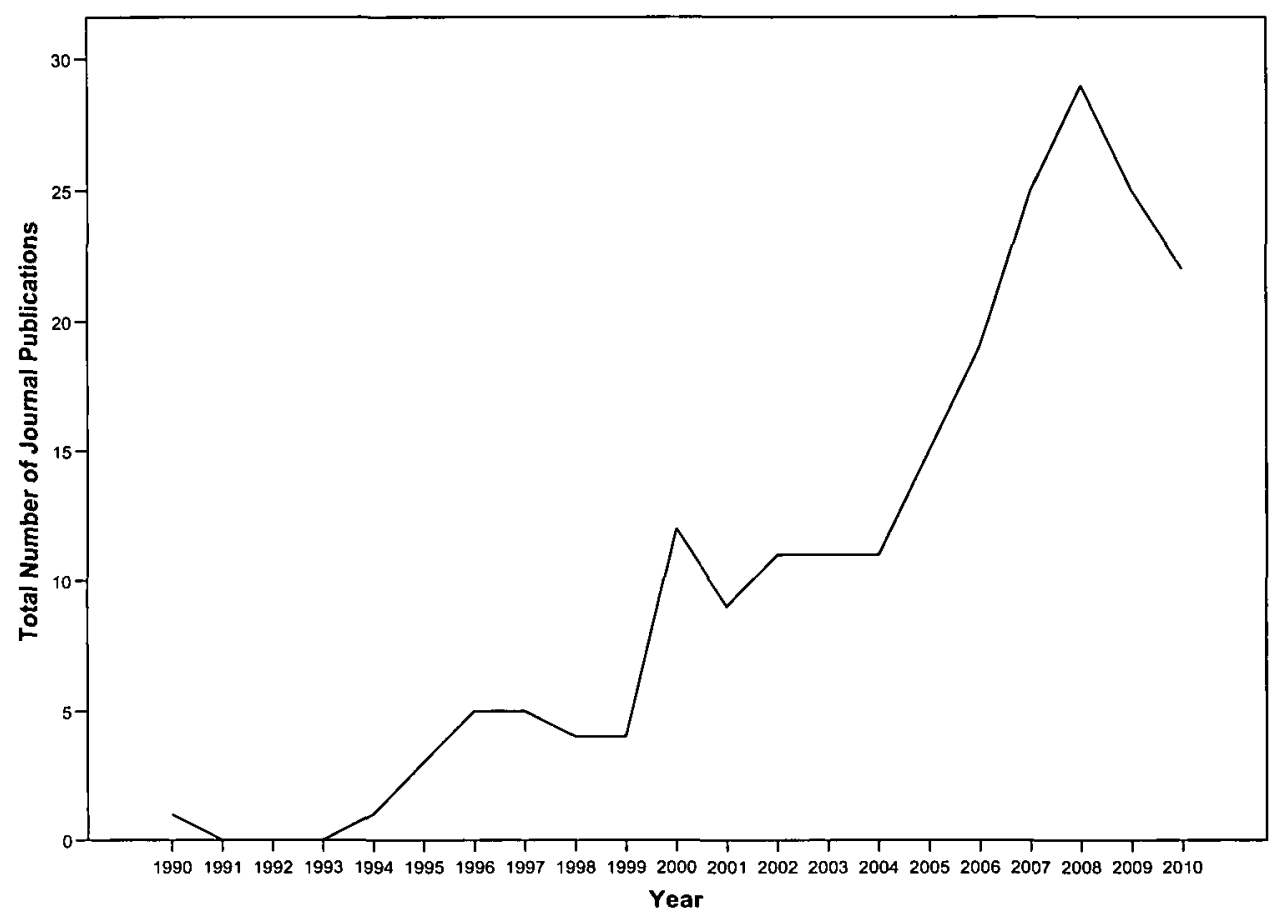

While guanxi is the common focus of all three streams, it is evident that there is a remarkable divide among them in terms of perspectives, theoretical foundations, and methodologies adopted. In this paper, we provide a comprehensive and integrative review of the research on guanxi at the micro (the individual and interpersonal) and macro (the organizational, industry, societal) levels by paying attention to: (i) various conceptualizations of guanxi; (ii) major theoretical perspectives on guanxi and its functions and consequences; and (iii) empirical research methods and findings regarding guanxi. Based on this review, we suggest new directions for future guanxi research.

\section{CONCEPTUALIZATIONS OF GUANXI}

Reflecting the richness, flexibility, and complexity of the Chinese language, the plethora of implicit and explicit definitions of guanxi challenges researchers. For example, guanxi has been referred to, separately or simultaneously, as relational entities and their relationships (e.g., Bian, 1997; Tsui \& Farh, 1997), as social practices of building and using personal relationships to get through life and work (e.g., Chen, Chen, \& Xin, 2004; Guthrie, 1998; Xin \& Pearce, 1996), as a strategy for organizations to gain competitive advantage (e.g., Li, Poppo, \& Zhou, 2008; Li \& Zhang, 2007; Park \& Luo, 2001; Peng \& Luo, 2000), and as 
a mechanism of contracting and transactions (Lovett, Simmons, \& Kali, 1999). Below, we discuss three different conceptions of guanxi to improve the precision of this concept and its conceptual foundations. They are broad typologies of: (i) guanxi ties; (ii) basic characteristics of dyadic guanxi; and (iii) units of guanxi analyses.

\section{Broad Typologies of Guanxi Ties}

The term guanxi in the Chinese language can refer to the state of being related between two or more entities, be they animate or inanimate, concrete or abstract (e.g., between two concepts), and human or non-human. The guanxi research covered here clearly refers to human relationships, which are often classified into several broad categories.

Family us. non-family guanxi. The distinction between family and non-family relations dates back to ancient China when Confucius prescribed a governance framework of five cardinal relations known as zou lun (五伦): emperor-official, father-son, husband-wife, elder brother-younger brother, and friend-friend (Bell, 2000; Confucius, 1915). Although family vs. non-family was a salient distinction, Confucian teachings emphasize their commonality and harmony with family relations the prototype and foundation of non-family relations - the essence of familial collectivism (Bond \& Hwang, 1986; Ho, 1998). For example, the father-son relation is prescribed as the model for the emperor-official relation and brotherhood as the model of friendship. One variant of family vs. non-family distinction is the ascribed/ preordained vs. achieved relations (King, 1991; Parsons, 1951) with the former referring to family, kinship, and birthplace and the latter to voluntary associations such as colleagues, schoolmates, and friendships. Another variant is the family vs. familiar or blood vs. social distinction (Jacobs, 1982; Tsang, 1998) where familiar and social relations refer to those who are non-family but are well acquainted.

Affective vs. instrumental guanxi. Social scientists who seek to capture the fundamental nature of family vs. non-family relations characterize the former as expressive and the latter as instrumental (Blau, 1964; Hwang, 1987; Yang, 1999). In Blau's theory of social exchange (1964) family and love oriented social interactions are motivated by the expression and maintenance of attraction and commitment to the intrinsic properties of the relationship per se whereas exchange relations are motivated by objectives of obtaining extrinsic benefits and rewards. Similarly, Hwang (1987), with explicit reference to Chinese guanxi, described family relationships as social-affective and non-family relationships as partially or wholly instrumental.

Personal/informal vs. impersonal/contractual guanxi. Personal/informal guanxi typically refers to interpersonal relations that carry characteristics of affect, obligation, and informality (Ho, 1999; Yang, 1999). In contrast, contractual guanxi typically refers to 
either interpersonal or inter-firm relations that are characterized by impersonality, legality, and formality (Blau \& Duncan, 1967; Davies, Leung, Luk, \& Wong, 1995; Lovett et al., 1999; Zhou, Li, Zhao, \& Cai, 2003). The personal/informalimpersonal/contractual typology is a useful distinction for business and work relationships in which family, social, and friendship ties are differentiated from formal, organizational, and professional relationships.

Mixed guanxi. Between the above contrasting guanxi types is the mixed guanxi type. For example, Hwang (1987) classified relationships into: socio-affective, instrumental, and mixed, which maps onto Yang's (1993) categories of jiaren (家人, familial), shouren (熟人, acquaintance) and shengren (生人, stranger) relationships that are also adopted by other researchers such as Tsui and Farh (1997), Jacobs (1982), and Fu, Tsui, and Dess (2006). Using a similar logic, Zhang and Zhang (2006) differentiated guanxi into obligatory (family and kinship relations), reciprocal (friends and acquaintances), and utilitarian (seller-buyers or strangers) and Fan (2002a) described family ties, friendship ties (helpers), and business ties.

Despite these different terminologies, however, there is a general consensus regarding differences in the nature of guanxi across the different typologies. Family, personal, and informal guanxi are relatively more affective whereas non-family, impersonal, and contractual guanxi are relatively more instrumental; and friends, colleagues, and acquaintances fall in between, although close friendship can be family-like. In the workplace and in business relationships, however, Chinese guanxi tends to be a mixture of family and non-family, personal and impersonal, and expressive and instrumental characteristics.

\section{Basic Characteristics of Dyadic Guanxi}

In examining more specific characteristics of a relationship between two parties, researchers have been focused on the following aspects of the relationship: guanxi bases, guanxi quality, and guanxi dynamics.

Guanxi bases. Guanxi bases usually refer to pre-existing particularistic ties between two interacting parties (Jacobs, 1982; Tsui \& Farh, 1997). Note that the two parties are already in an ongoing relationship, which may or may not have some preexisting guanxi bases. Both the existence and the different types of guanxi bases affect the quality of the ongoing dyadic interaction. Researchers have identified a host of shared social identities such as kinships, surnames, alumni (schoolmates or classmates), birthplace, workplaces (military and civilian), or political party affiliation. These shared social identities differ from demographical similarities typically studied by diversity researchers in the West, such as race, gender, and age (Tsui, Egan, \& O'Reilly, 1992; Tsui \& Farh, 1997). In addition to shared social identities, 
a guanxi base may be simply a third party who is known to two otherwise unrelated parties (Bian, 1997). In contrast to pre-existing shared social ties, 'anticipatory guanxi bases' (Chen \& Chen, 2004: 311 ) refer to shared visions and aspirations that lead to new joint ventures and activities between parties who come into contact without pre-existing guanxi. Such new joint ventures, once initiated and accomplished, serve as substantive pre-existing guanxi bases for future guanxi building and exchange.

Guanxi quality. Guanxi types or bases often assume some associated quality. Family ties are assumed to be strong and close as they are driven by affective motives whereas impersonal non-family ties are weak and distant as they are driven by instrumental motives (Hwang, 1987). There is also an assumption of different levels of trust, interdependence, and obligation between parties with guanxi and those without, or between strong and weak guanxi (Bian, 1997; Peng \& Yang, 1999; Yang, 1999; Zhang, 1999). Most research on guanxi, however, examined effects of guanxi types, assuming but not explicating or measuring, guanxi quality.

Guanxi dynamics: Strategies, practices and processes. Scholars of guanxi research at the firm level use guanxi as a term for social networking as a competitive strategy (Luo, 2001; Luo et al., 2012; Park \& Luo, 2001; Peng \& Luo, 2000). Guthrie (1998) used the term guanxi practices to refer to the use of personal relations for achieving any objectives in work and life. Chen et al. (2004) defined guanxi practices in human resource management (HRM) as the extent to which personnel selection, performance appraisal, and rewards allocation are based on guanxi ties. In the supervisor-subordinate guanxi research (Chen et al., 2009; Law, Wong, Wang, \& Wang, 2000) guanxi activities outside the work setting were used as indicators of strong guanxi quality.

There have been a number of theoretical models on the dynamic processes of guanxi building, maintenance and use in a variety of fields such as management, marketing, and total quality management at individual and organizational level (Chen \& Chen, 2004; Peng \& Yang, 1999; Su, Mitchell, \& Sirgy, 2007; Wong, Leung, Hung, \& Ngai, 2007; Yau, Lee, Chow, Sin, \& Tse, 2000). These models tend to present a more in-depth treatment of the guanxi phenomenon including the historical, cultural, and linguistic root meanings of the term, and differentiate among guanxi bases, guanxi building processes, guanxi quality, and outcomes. For example, at the interpersonal level, Chen and Chen (2004) proposed a process model of guanxi development, in which social ties serve as guanxi bases, interactive activities (guanxi strategies) are distinguished from guanxi objectives, and guanxi quality (e.g., guanxi closeness) is an indicator of the state of a relation at a given point in time. At the organizational level, Su et al. (2007) proposed a model in which guanxi management of internal and external major stakeholders is positively associated with relationship quality, which enhances firm survival through the mediation of access to critical resources. 
We see two weaknesses in the area of guanxi processes. One is the lack of empirical research to test these theoretical models. The other is that some of the process models proposed a large number of intricately related indigenous guanxi terms without explicating the essential meanings of each construct or making clear conceptual distinctions and similarities between different constructs. To guide empirical research and to accumulate knowledge indigenous terms must be adequately conceived and operationalizable so that their discriminant, convergent, and construct validities can be tested.

\section{Units of Guanxi Analysis}

Earlier we commented on the richness, flexibility, and context dependence characteristics of the Chinese language that pose challenges for the accuracy and specificity of guanxi conceptualization. The same applies to the units of analyses in guanxi research. For example, as a noun in reference to social relations, the word guanxi contains within itself no marker of singular or plural or the level of the unit, such that guanxi can refer to a guanxi person, a guanxi relation, or a guanxi net depending on the context within which it is used. Yet, the specification of the level of theory and analysis, namely, the level of the focal unit at which theory and analyses are applied is critical for scientific research (Hitt, Beamish, Jackson, \& Mathieu, 2007).

In network terminology (Brass, 1995), a focal actor within a social network is the ego whereas the party with whom the ego is connected to is an alter. The ego and the alter are each called a node and two connected nodes form a tie. Two and more ties then make up a net, which is called a network of inter-connected ties. There are therefore three units of analysis in social network research: the individual (node); the dyad (tie); and the network (system). To enhance research quality and to connect guanxi research in China to social network research elsewhere, it is important to specify the unit of analysis. Useful unit designations include guanxi ego/alter, (interpersonal/intergroup/interfirm) guanxi dyads, and guanxi nets (of individuals/groups/firms). The actor within a social network can be an individual, a group, or an organization. Cross-cutting network units of analyses with those of the actor, we can see areas into which past guanxi research has fallen. As can be seen in Table 1, much of the research on guanxi ties is concentrated on the interpersonal dyad relations of individual actors even for macro researchers on firms (Peng \& Luo, 2000; Xin \& Pearce, 1996). Network level studies of group and firms are clearly lacking.

We observe that in Western social networking research, dyadic ties have received limited attention from researchers because such ties are structurally embedded in the system of a social network. This is evident in Moran's (2005: 1132) lament that 'Unfortunately, dyad-specific qualities of social capital have been given much less empirical attention [and] have not been empirically 
Table 1. Number of journal articles by units of analysis of guanxi actors and networks

\begin{tabular}{clll}
\hline \hline Actor & \multicolumn{1}{c}{ Individual } & \multicolumn{1}{c}{ Group } & \multicolumn{1}{c}{ Organization } \\
\hline \multirow{2}{*}{ Network } & & & \\
Node & Individual characteristics & Group characteristics & Organizational characteristics \\
& 13 & 1 & 10 \\
Tie & Interpersonal tie & Inter-group tie & Inter-organization tie \\
& 35 & 0 & 25 \\
Network & Ego-centric network & Group network & Organizational network \\
& 15 & 0 & 15 \\
\hline \hline
\end{tabular}

Notes:

1. Only articles that have been cited in this paper are counted.

2. Articles in Each Cell are as follows.

Individual characteristics: Bian, 1997; Bian \& Ang, 1997; Bu \& Roy, 2008; Chen \& Chen, 2009; Chow \& Ng, 2004; Giles, Park \& Cai, 2006; Farh et al., 1998; Luo, 2001; Peng \& Yang, 1999; Shin et al., 2007; Su et al., 2003;

Zhang, 1999; Zhang \& Li, 2003

Group characteristics: Chen et al., 2011

Organizational characteristics: Chen et al., 2011; Li \& Zhang, 2007; Luo, 2003; Luo ct al. 2004; Park \& Luo, 2001; Su ct al. 2009; Su et al., 2003; Xin \& Pcarce, 1996; Zhang \& Keh, 2009; Zhou et al., 2003

Interpersonal ties: Alston, 1989; Bond \& Hwang, 1986; Chen \& Chen, 2004; Chen \& Chen, 2009; Chen et al., 2004; Chen \& Peng, 2008; Chen et al., 2009; Chen \& Tjosvold, 2006; Dunfec \& Warren, 2001; Fan, 2002a; Fan, 2002b; Farh et al., 1998; Guthrie, 2002; Han \& Altman, 2009; He et al., 2009; Ho \& Redfern, 20l0; Hwang; 1987; Jiang et al., 201 1; Law ct al., 2000; Li et al., 201 1; Luo, 2001; 2008; 2011; Morris et al., 2008; Provis, 2008; Song et al., 2012; Sue-Chan \& Dasborough, 2006; Tsui \& Farh, 1997; Wong et al., 2003; Wong \& Ellis, 2002; Wong et al., 2007; Yang, 1999; Yang, 2000; Zhuang \& Xi, 2003

Intergroup ties: (None)

Inter-organization ties (*indicate truly inter-organization guanxi ties; all others used interpersonal ties at the organization level): Chen et al., 2010a*; Chen et al., 2010b; Davies et al., 1995; Gao et al., 2008; Jiang \& Jin, 2008; Jiang et al., 2009; Liu et al., 2008*; Luk et al., 2008; Luo \& Liu, 2009; Nolan, 2010*; Peng \& Luo, 2000; Ramasamy et al., 2006*; Su et al., 2009; Tan et al., 2009*; Tsang, 1998; Tung \& Worm, 2001*; Wang, 2007; Wank, 1999*; 2002*; Warren et al., 2004; Wu et al., 2008; Xin \& Pearce, 1996; Zhou et al., 2003*; Zhuang et al., 2010

Individual net: Bian, 1997; Bian \& Ang, 1997; Bu \& Roy, 2008; Chow \& Ng, 2004; Chua et al., 2009; Giles et al., 2006; Jacobs, 1982; King, 1991; Lin \& Si, 2010; Lin, 1982; W.-P. Wu, 2008; Xiao \& Tsui, 2007; Yang, 1993; Zhang, 2006; Zhang \& Li, 2003

Group net: (None)

Organizational net (* indicates truly inter-firm guanxi ties; all others aggrcgated interpersonal tics to the firm level): Buckley et al., 2006*; Chen et al., 2011a; Ellis, 2011; Gu et al., 2008; Luo et al. 2004; Luo, 1997b*; Luo, 2001*; Luo, 2003; Luo et al., 2002; Standifird \& Marshall, 2000*; Su et al. 2007*; Zhang \& Li, 2008; Zhang \& Kch, 2009*; Zhang \& Zhang, 2006; Zhao \& Hsu, 2007

disentangled from social capital's structural attributes'. In contrast to the Western structural view of dyadic ties, person-to-person relation is a general and diffused topic in Chinese guanxi research. Chinese guanxi is a distinct research domain that subsumes social network research, leader-member-exchange, and relationship making at all levels. This is because, while the dyadic guanxi may serve as building blocks of a social network, it can and often does transcend the network, and the dynamics of personal exchanges may unfold inside or outside the social network (Parnell, 2005). Nevertheless, there are a significant number of 
guanxi studies that apply social network theories and techniques (e.g., Bian, 1997; Bian \& Ang, 1997; Chua, Morris, \& Ingram, 2009; Morris, Podolny, \& Sullivan, 2008; Xiao \& Tsui, 2007), although most of the actors are individuals rather than organizations. The social network techniques allow guanxi researchers to examine the dynamics of both the dyadic relationships (e.g., Chua et al., 2009) and the structural effects of the embedding social network on personal relationships. Additionally, a common social network framework allows more direct dialogue and comparisons between Chinese and Western research (e.g., Bian, 1997; Xiao \& Tsui, 2007).

\section{THEORETICAL PERSPECTIVES ON GUANXI AND SOCIAL NETWORKING}

With broad research interest in guanxi from the diverse disciplines of economics, sociology, psychology, and business management, a great varicty of theoretical frameworks and perspectives has been employed. It is difficult to derive an overarching theoretical framework that encompasses these diverse perspectives. We identify three perspectives implicitly assumed or explicitly used in the guanxi literature: (i) ego-pragmatic; (ii) community-ethical; and (iii) Confucian-relational. These perspectives differ as to their theoretical foundation, aspects of guanxi, and assessments of guanxi in terms of the costs and benefits to guanxi parties and to large communities.

\section{The Ego-pragmatic Perspective}

The ego-pragmatic perspective of guanxi is the dominant perspective in guanxi research in the sociological and organizational literatures. Social capital theory conceives social ties and networks as possessed by the individual parties, which may or may not transfer to the organizational level (Burt, 1992; Van Buren \& Leana, 2000). Guanxi ties and networks are seen as social resources (Bian, 1997; Hwang, 1987; Lin, 1982; Luo, 1997a) that people develop and deploy for attaining favours and benefits such as better job placement and career success for individuals (Bian, 1997; Bian \& Ang, 1997; Xiao \& Tsui, 2007) and organizational performance for firms (Li et al., 2008; Luo et al., 2012; Park \& Luo, 2001; Peng \& Luo, 2000; Tsang, 1998). Apart from social capital theory, firm-level guanxi research relies on institutional theory (North, 1990), the resource-based view of the firm (Barney, 1991), resource dependency theory (Pfeffer \& Salancik, 1978), or transaction cost economics (Coase, 1937); whereas the individual and interpersonal guanxi research relies primarily on theories of social exchange (Blau, 1964; Homans, 1958), leadermember exchange (Graen \& Uhl-Bien, 1995), and interpersonal trust focusing on principles of reciprocity, equity, and face (Hwang, 1987). The essential nature 
of guanxi interaction is the exchange of rewards and benefits for the focal actors. The egocentric perspective tends to focus on testing and documenting the egoenhancing effects of guanxi.

Some caveats, however, emerge from this line of research, which questions the benign outcomes of guanxi practices in organizations and business transactions. First, although guanxi should not be equated with corruption and cronyism (Khatri, Tsang, \& Begley, 2006; Lovett et al., 1999), itse corrosive downside, albeit often accompanied by the justification that weak institutional environments necessitate it, is acknowledged by academics (Bian, 1997; Lovett et al., 1999; Xin \& Pearce, 1996). Second, even from an egocentric perspective, guanxi transactions require skillful management of resource dependency and constituent hierarchy within and outside organizations (Su et al., 2007) and it can be argued that their benefit is short term and tactical rather than long term and strategic (Fan, 2002b). Third, researchers adopting a community-ethical perspective raise issues of negative externalities inherent in guanxi practices that impact on the collective interests of the organization and society (Chen \& Chen, 2009), on the merit-based system of modern organizations and the market efficiency of modern societies (Dunfee \& Warren, 2001), and on the development and functioning of professional and public morality (Fei, 1992/1947).

\section{The Community-ethical Perspective}

In contrast to the ego-pragmatic perspective, the community-ethical perspective explores the corrosive aspects of guanxi ties and guanxi practices within organizations and society at large. This perspective appeals to the normative theories of morality and ethics in international business (De George, 1993; Donaldson, 1996) and theories of social dilemmas (Dawes, 1980) and multiple stakeholders (Fan, 2002b). Dunfee and Warren (2001) challenged the dominant descriptive and instrumental perspective of guanxi research and proposed a normative perspective that analyzes the ethicality of guanxi practices (the uses of guanxi), identifing guanxi acts that are potentially unethical. Guanxi acts are unethical when they benefit the individual, the few, and the privileged at the expense of the community, the many, and the less privileged, and when they violate important fiduciary duties (prescribed to the guanxi users), local social norms of justice and fairness, and the universal hyper-norms of the larger community (Dunfee \& Warren, 2001). Additionally, Lin and $\mathrm{Si}(2010)$ argued that the Chinese guanxi networks were formed under conditions of resource scarcity and characterized by dense (multiplex) strong ties and sparse weak ties. Such unique socio-economic and cultural conditions of Chinese guanxi networks are more likely to lead to market fragmentation, state intervention, and rent-seeking.

Provis (2008) discussed two different types of obligations: personal and social obligations as owed to guanxi parties vs. general and abstract moral obligations 
as owed to impersonal communities and to the rational structure of law and administration. The private ethics of guanxi exchange, such as reciprocity and trust between guanxi parties, may nevertheless conflict with and violate the public ethics of the community and the rule of law, impartiality and fairness (Fei, 1992/1947). Similarly, from a social dilemma perspective, Chen and Chen (2009) theorized on the negative externalities of close personal relationships in modern formal organizations and how strong social and emotional personal identification between guanxi parties may lead to the sacrifice of collective interests for the benefit of self-interest.

One theme that emerges from ethical considerations of guanxi practices (with favour exchanges as the core activities) is that they are ethically acceptable or even laudable if contained within the private domain and personal and private resources are exchanged (Su \& Littlefield, 2001). However, when personal and organizational resources or private and public resources are mixed up in guanxi exchanges, they become ethically complex. Using public resources to benefit the private interests of guanxi parties violates the ethical rules and norms of the relevant communities (Chen et al., 2004; Jiang, Chen, \& Shi, 2011; Luo, 2008; Tsang, 1998).

\section{The Confucian Relational Perspective}

The Confucian relational perspective of guanxi can probably be better captured by the term 'relationalism' (Chen \& Chen, 2009; Hwang, 2009; King, 1991). Relationalism refers to a social, organizational, and moral system in which personal and small group relationships take precedence over both the needs and interests of the individual person and those of general and impersonal relationships found in large organizations and communities (Fei, 1992/1947; Hwang, 2009; King, 1991; Liang, 1977/1949; Yang, 1993). In defining and illustrating relationalism, Confucian scholars have generally taken a comparative approach, contrasting traditional Confucianism with Western modern theories of organization and management, including theories of social exchange (Blau, 1964; Chai \& Rhee, 2010), leadermember-exchange (Graen \& Uhl-Bien, 1995), transaction cost (Lovett et al., 1999), and normative theories of morality and ethics (De George, 1993; Donaldson, 1996).

With the recognition that scholars may differ in focus and interpretation we attempt to abstract a few common characteristics of Confucian relationalism that we consider to be most relevant to guanxi theories and research. First, as the basic unit of social systems, personal relationship is of paramount importance. The Chinese people and society are said to be relation based as opposed to individual or (large) group based (Hwang, 2009; King, 1991), dominated by relationships (Ho, 1998), and so relationship oriented that guanxi is pursued for its own sake (Yang, 1993). Second, with its prevalence and importance in Chinese society, dedication and commitment to personal relationships, especially between the most particu- 
laristic and close ones, signifies the humaneness of a person and a society. Confucian relationalism is therefore hailed as representing the true human relationship in 'the perfect sense of the term' (Bell, 2000), meaning a relationship in which individual parties are committed to the intrinsic relationship itself regardless of considerations of extrinsic costs and benefits (Blau, 1964; Hwang, 2009). This type of commitment to relationship is holistic and all-embracing in that it involves the care and concern for social, psychological, and economic welfare of the whole person across life domains (Chen et al., 2009; Fiske, 1992). Exemplifying such a commitment, family or family-like relationships have been held as the ideal prototype of Confucian organization and governance, leading to the blurring of organizational boundaries between family and business, and private and public, as well as between personal and professional relations.

Third, not all personal relations are equal but are differentiated according to the degree of particularism, namely, how close or distant the alters are to the ego. Consequently, prior to or during social interactions the Chinese often gauge the nature of the relation by categorizing others into family, familiar, and stranger (Hwang, 1987; Luo, 2011). Other commonly used social categories include kinship, birth place, schoolmate, comrade in arms, and so on (Farh, Tsui, Xin, \& Cheng, 1998; Jacobs, 1982). These pre-existing ties may either obstruct or facilitate formal and official relationships in organizations. Chinese relations are differentiated not only between different categories (according to particularism or closeness) but also within a given relationship in terms of hierarchy according to position, gender, and age. Such hierarchical relations are governed by different but reciprocal role obligations, such as the superior providing holistic consideration whereas the subordinate shows loyalty (Chen et al., 2009; Farh \& Cheng, 2000).

Lastly, due to the above characteristics of particularism and hierarchy, Confucian relationalism is elaborate and specific about interpersonal and role based ethics but ambivalent and situational about universal ethics (Fei, 1992/1947; Hsu, 1963; Liang, 1977/1949). Indeed the Chinese term lunli (ethics) literally means 'relationship appropriateness' even though it is now commonly understood as a generic term for ethics. When Chinese guanxi is compared with Japanese wa and Korean inhwa (Alston, 1989), the Arab world's wasta (Hutchings \& Weir, 2006), and Russian blat (Michailova \& Worm, 2003), authors tend to point out their similarities, such as the importance of familial and personal relationships, ingroupoutgroup distinctions, and the exchange of favours. Interestingly, while guanxi tends to have neutral or even positive connotations in China, wasta in the Arab world and blat in Russia have a negative connotation.

Although some scholars view the Confucian personal commitment to relationship as more humane than the Western impersonal instrumental relationship, scholars taking an economic transaction cost perspective view it as a matter of modes of control in dealing with fundamental agency problems (Lovett et al., 1999). These researchers emphasize the rawness and the pure instrumentality of business guanxi in 
China (Fan, 2002a; Luo, 1997b; Park \& Luo, 2001). The use of personal guanxi is a competitive strategy, largely necessitated by the immature legal and economic institutions in China. Su and Littlefield (2001), in an attempt to tease out guanxi practices ingrained in the Chinese relational tradition and those adapting to the immature institutional environment, proposed two types of guanxi practices, namely qinyou guanxi (亲友关系) (personal favour exchanges among family and friends) and quanli guanxi (权利关系) (exchange between power and interests), attributing the former to the influence of Confucian relationalism and the latter to that of the contemporary institutions. Furthermore, the authors held the former as a legitimate means of navigating through everday work and life but the latter as corrupt and rent-seeking activity exclusive to the elite, the powerful and the wealthy.

Lovett et al. (1999) contend that in a more globalized economy characterized by rapid technological advancement and high socio-political uncertainty, the strength of both the Eastern guanxi system and the Western market system is required. The West relies overly on impersonal/universal rules and focuses on discrete short-term transactions, while the East relies sometimes overly on the attachment and benevolence of the ingroup to the neglect of ability and integrity. Ip (2009) argued that familial collectivism fell short of meeting the challenges inherent in global firms because of its emphasis on hierarchy and particularism. Yet, Davies et al. (1995) contend that Eastern and Western business practices are likely to become more similar in the 21 st century as Western business practices adopt more guanxi-type practices of building and relying on personal relationships of trust and reputation while Eastern business practices will rely more on rules and regulations. To us the opposing interpretations of Chinese guanxi (i.e., the intrinsic value vs. the instrumental use of personal relationship) represent two extremes of a continuum of interpersonal relationships. This reflects the paradoxical challenges of Chinese guanxi in an increasingly marketized modern China. Clearly, Chinese guanxi is a complex phenomenon and its meanings, practices, and functions will be better understood when examined from multiple theoretical perspectives and multiple levels of analyses.

\section{EMPIRICAL RESEARCH ON GUANXI AND SOGIAL NETWORKING}

This section summarizes the major empirical findings of research on guanxi and social networking. We divide the summaries into four sections: (i) the micro level of individuals and interpersonal relationships; (ii) the macro levels of firm, industrial, and societal relationships; (iii) guanxi practices and ethics; and (iv) cross-cultural comparisons.

\section{Empirical Research at the Micro Level}

In this section, we discuss research methodologies used in studying guanxi, the measurement of guanxi quality, and research findings. 
Research methodologies. Three major research designs have been used including surveys, semi-experiments, and interviews. Most guanxi research uses one of two survey methods. One is the ego-centric network nomination method, through which the ego nominates alters in the ego's social networks and provides information about key elements of the network (Bian, 1997; Bu \& Roy, 2008; Chow \& Ng, 2004; Chua et al., 2009; Hom \& Xiao, 2011; Xiao \& Tsui, 2007). The other is the regular paper and pencil questionnaire consisting of questions about relevant guanxi constructs without mapping out each focal person's social networks (Chen et al., 2004; Chen \& Peng, 2008; Su, Yang, Zhuang, Zhou, \& Dou, 2009; Warren, Dunfee, \& Li, 2004; Xin \& Pearce, 1996). One advantage of the network recall method is that when data is generated from one source, the same source bias problem is considered less serious because network characteristics can be abstracted from the data by the researcher rather than directly reported by the respondents. However, because network nomination can be tedious and time consuming, it leaves limited space and time for questions regarding dynamic interactions among network members. Chua et al. (2009) represented a creative combination in which they used the network nomination method and well established but short measures of different types of trust to compare differences between Chinese and American managers in their interpersonal relationships.

Although used less frequently than the survey method, semi-experiments are also used for guanxi research. For example, behavioral events of interpersonal interactions (Chen \& Peng, 2008), ethical dilemmas involving different role prescriptions (Tan \& Snell, 2002), different guanxi bases used in company human resource management decisions (Chen et al., 2004), and consequences of guanxi practices to different levels of communities (Warren et al., 2004) are systematically manipulated to observe their effects on relationship quality, and on the attitude, perception, and ethical decision making of the subjects. Apart from surveys and semi-experiments, few studies have used in-depth interviews to explore the dynamics and consequences of guanxi use (e.g., Xin \& Pearce, 1996; Zhang, 2006).

While each of the above research methodologies and designs has its advantages and disadvantages and its appropriateness often depends on the research questions asked, we encourage a combination of the different methods for conceptual precision and for triangulation of empirical results. Examples include the combination of network recall and interview (Xiao \& Tsui, 2007), semi-experiment with survey (Chen et al., 2004), and the construction of guanxi as a political connection through secondary data (e.g., Chen, Li, \& Liang, 201 la).

Measurements of guanxi quality. We found a variety of ways in which guanxi quality is defined and operationalized. Bian and colleagues conceived guanxi strength in terms of intimacy and trust (Bian, 1997; Bian \& Ang, 1997) but operationalized it in terms of familiarity, that is, how well the guanxi parties know each other. Guanxi quality can also be measured as the degree of closeness or distance between the ego 
and its alter in the egocentric network (Chen \& Chen, 2004; Fu et al., 2006). Alternatively, guanxi quality is conceived as the quality of social exchange activities, such as social exchanges outside of work between a subordinate and supervisor (Law et al., 2000). Further, guanxi quality is conceived as the extent to which a work (presumably more instrumental) relationship is modeled on or transformed into a family-like, communal sharing relationship (Bell, 2000; Bond \& Hwang, 1986; Chen et al., 2009; Fiske, 1992; Yang, 2000); outside work social exchanges serve as an indicator of such transformation.

Given that guanxi quality is an important construct, it is worth taking a closer look at the four measurements of guanxi quality. The first scale was created by Law et al. (2000) to differentiate leader-member guanxi (LMG) from the American leader-member exchange LMX (as measured by Scandura \& Graen, 1984). Law et al. (2000) and similarly Wong, Ngo, and Wong (2003) defined LMG as personal relationship quality but operationalized it as predominantly non-work related social exchange acts, such as gift giving and dinner invitations. The second measure of supervisor-subordinate guanxi quality, developed by Chen et al. (2009), is composed of three dimensions: affective attachment, inclusion of personal life into workplace relationship, and deference to supervisor. Thirdly, Chen and Peng (2008) created a scale of peer relationship quality at work. Lastly, not labelled as guanxi, the leader-member exchange (LMX) scale (e.g., Fairhurst \& Chandler, 1989; Liden \& Maslyn, 1998; Scandura \& Graen, 1984), developed in the West, has been used by Chinese scholars to measure Chinese supervisor-subordinate work relationships. The LMX scale is comprised of multi-aspects (e.g., Liden and Maslyn, 1998) as well as a general one dimension (e.g., Scandura \& Graen, 1984).

The major difference between the Chinese guanxi quality measurements and the LMX is that the former includes social exchanges outside work whereas LMX is limited to personal relationships at work. The inclusion of non-work related social exchange has the advantage of capturing a mixture of the affect and instrumentality of Chinese guanxi. Nevertheless, the multi-aspect measure as developed by Liden and Maslyn (1998), which incorporates affect elements in LMX, should make up some disadvantage of the uni-dimensional measure. Between the two Chinese supervisor-subordinate guanxi quality measurements (i.e., Chen et al., 2009; Law et al., 2000), Chen et al.'s (2009) has the advantage of encompassing both work and non-work relationships and is more conceptually equivalent to the LMX measurement.

Research findings. We organized the findings into four groups: (i) the prevalence of guanxi ties; (ii) antecedents of guanxi ties or quality; (iii) the effect of demographic backgrounds; and (iv) outcomes of guanxi ties and guanxi quality.

The prevalence of guanxi ties. How pervasive are work and business relationships based on guanxi ties? In a sample of 560 supervisor-subordinate dyads of salespeople 
from an insurance company in Taiwan (Farh et al., 1998), pre-existing ties, such as former classmate, former neighbour, relatives, same last name, same natal origin, former colleague, were not as pervasive because they occur at a lower rate, ranging from 2.1 percent to 3.4 percent. In a sample of thirty-two executives and their business relationships totaling 212 dyads from mainland China (Farh et al., 1998), the majority (82.4 percent) of the executives' business relationships were based on regular work ties; classmates made up a remote second ( 10.7 percent), followed by relatives (4.4 percent) and natal origin (2.4 percent). In Bu and Roy's (2008) ego-centric network data of 105 senior- and middle-level managers from stateowned, private, and foreign invested firms in mainland China, most of the network ties were formed through work ( 60 percent) or non-work (25.6 percent) interactions rather than through pre-existing ties such as kinship (3.5 percent) or pre-career friendship ties (11 percent) such as those from schools or the military. It is worth noting that the percentage of pre-existing guanxi at intact work units is much lower than that in the ego-centric networks because employees and managers have more discretion in selecting particularistic ties. The general finding is that the Chinese create most of their work and professional relationships through work and social interactions with new partners rather than being limited to pre-existing kinship or friendship ties. These findings suggest that the prevalence of pre-existing ties in Chinese work relationships may be a myth and most are formed on the basis of anticipatory guanxi (Chen \& Chen, 2004).

Antecedents of guanxi ties or guanxi quality. Based on over a thousand associate ties nominated by $72 \mathrm{MBA} / \mathrm{EMBA}$ respondents, Chow and $\mathrm{Ng}$ (2004) explored the effect of various guanxi bases on relationship closeness and on the number and type of network contents. In general, respondents are more likely to feel closer to family ties than to non-family ties. However, with non-family ties, the respondents are more likely to report close relationships with former classmates, social club members, and family friends but distant relationships with work colleagues and with relatives. For soliciting help, contrary to expectations, respondents are more likely to select non-family close ties than family ties for all given areas except in a crisis situation. The authors interpreted the last finding as: (i) the bond within the family is not as strong; and (ii) family ties would lead to stronger obligations than non-family ties. We agree with the second but not so much the first interpretation because except for crisis and socializing, all the areas for which help was sought were work and career related and family members may not have the ability or resources to help with those issues. Zhu, Chen, $\mathrm{Li}$, and Zhou (2009) also found subtle differences in the effect of kinship (relatives) vs. friendship ties on relationship closeness at work. In a study of non-owner managers, the authors found while owner-manager friendship ties and kinship ties were both positively related to psychological ownership of the family business, friendship ties did so through developing guanxi closeness at work while kinship ties were not significantly related 
to guanxi closeness at work. Chen and Peng (2008) found co-worker relationship closeness was enhanced by positive behavioural incidents but weakened by negative ones.

To the extent trust indicates guanxi quality, studies of the effects of guanxi bases or exchanges on trust become relevant. Farh et al. (1998) found that mainland Chinese executives reported a higher level of trust when their business relationships were based on guanxi ties than when based on regular work ties. Wong et al. (2003) found that social interactions and exchanges outside work related positively to trust in supervisor. Taking an attribution approach, Jiang et al. (2011) found trust in supervisor to increase when supervisor favours are seen as rewards for performance (i.e., merit attribution) but decrease when they are seen as payback for personal favours to the supervisor outside work (personal favour attribution). Merit attribution also enhances the positive effect of supervisor favours on trust. Luo (2011) found Chinese workers to have as much trust in familiar ties as in friendship ties and that they converted unfamiliar to familiar ties when the former become trustworthy.

The effects of demographic backgrounds. A few studies have examined the effects of relational or individual demography on guanxi quality or guanxi practices. Age similarity is found to be related to personal relationship closeness of full time Hong Kong employees attending MBA/EMBA classes (Chow \& Ng, 2004). However, for network ties within a company, the alter is generally older than the ego for Chinese senior and middle level managers (Bu \& Roy, 2008). Chua et al. (2009) found more ties in which the alter is ten or more years older than the ego in the networks of Chinese managers than in those of American managers. With regards to gender, $\mathrm{Bu}$ and Roy (2008) found that, similar to earlier studies of American managers (Ibarra, 1992, 1997), the Chinese male managers' career network was predominantly homophilous (79 percent of ties with the same sex and 21 percent with the opposite sex), whereas the female managers' career network was predominantly heterophilous (78 percent with the opposite sex but 22 percent with the same sex). Furthermore, although the general pattern of age difference is that the alter is older than the ego, such differences do not apply to ties in which the ego is the male and the alter is the female. Finally, while there is no significant effect of gender on face-to-face interactions within the workplace, the effect is remarkable for outside work interactions. Chinese female managers who form personal ties (as opposed to ties that overlap with formal positions) with males are much less likely to socialize outside the workplace than male-male, male-female, and female-female career ties. A recent study (Song, Cadsby, \& $\mathrm{Bi}$, 2012) found trust is engendered with guanxi ties (anonymous classmates) but not with demographically similar classmates, confirming Farh et al.'s study (1998) that the guanxi tie is more important than demographic similarity for trust.

Shifting the context from urban to rural areas, studies of kinship guanxi and non-farm employment show that women benefited more from the local labour 
market than males and marriage negatively affected non-farm employment for women but not for men (e.g., Zhang \& Li, 2003). Rural women relied heavily on kinship, friendship, and hometown ties in obtaining jobs and in dealing with work and life challenges in the city(Zhang, 2006); reliance on such guanxi ties had drawbacks, such as being channelled into low-paid gender specific jobs with limited upward mobility.

Outcomes of guanxi ties and guanxi quality. Bian's (1997) pioneering research found significant positive effect of guanxi tie strength on job searching in China in 1988 when government authorities controlled employment. Using a household survey of 1,008 adults, Bian found that job searchers used strong guanxi ties more frequently than weak ties to successfully find jobs. The study also found that both direct and indirect guanxi ties were used to obtain help from job-assigning authorities, but using indirect ties led to better jobs than using direct ties. Finally, the intermediary ties tended to have strong ties with both the job seeker and the helper.

While Bian's (1997) study was conducted in an urban environment and during a period when the open labour market was lacking, the importance of guanxi in job search and placement was also found in rural areas when economic reform had spurred labour migration from farms into towns and cities. Using data from a rural household survey in Northeast China, Zhang and Li (2003) studied how non-farm employment was facilitated by three types of kinship guanxi ties: family members and relatives who (i) helped job search; (ii) resided outside the region; and (iii) were local cadres. The authors pointed out that the effect of cadre guanxi on formal local jobs demonstrated nepotism and discrimination as a function of social networks.

Research in China that gauges relationship quality through LMX (for a more detailed review, see Chen \& Farh, 2010) showed positive effects such as enhancing $\mathrm{OCB}$, job satisfaction, task performance, and reducing withdrawal behaviour of the subordinates (Aryee \& Chen, 2006; Hackett, Farh, Song, \& Lapierre, 2003; Hui, Law, \& Chen, 1999; Liang, Ling, \& Hsieh, 2007). It also increased participative decision making and constructive controversy between managers and their subordinates (Chen \& Tjosvold, 2006, 2007). Chen and Tjosvold (2007) compared the effects of LMG and LMX and found that: 1) LMX tended to have more significant effects than LMG; and 2) the positive effect of LMG was significant in ChineseChinese manager-employee dyads but not in Chinese-American dyads. In the study by Law et al. (2000), when both LMG and LMX were present, LMG was positively related to the subordinate's probability of receiving bonus allocation and promotion, but not to performance rating or task assignment; LMX on the other hand was related to all four outcomes, although the effect on performance rating was only marginally significant. What is striking, however, is that the effect of LMX on job assignment, promotability, and bonus allocation were all mediated by performance rating whereas the effects of LMG were not. Similarly, Hu, Hsu, and Cheng (2004) 
found that workers who have better guanxi with supervisors received higher reward; Zhang and Yang (1998) found that when allocating rewards, supervisors also took their guanxi with subordinates into consideration, which the authors attributed to the so-called principle of affect and rationality (he qing he $l i$ 合情合理). These studies suggest that Chinese supervisors may allocate rewards not purely on the basis of performance merits but on personal relationships, which could lower trust in the supervisor (Chen et al., 2004; Jiang et al., 2011).

A few studies examined how guanxi was related to knowledge sharing in organizations. In an organization in which employees work in distant locations, He, Qiao, and Wei (2009) found that the knowledge management system installed by the organization was more likely to be used for knowledge sharing when trustworthy guanxi ties were established among employees. Similarly, Shin, Ishman, and Sanders (2007) found that in-group membership (where guanxi quality is high) explained nearly 30 percent of the variance in information sharing behaviour within an organization.

\section{Empirical Research at the Macro Level}

Most macro level studies were investigating the organizational level outcomes of the aggregated inter-personal ties that the top management team or boundary personnel have with persons in other entities. The empirical research at the macro level covers firm, industry, and international relationships although the majority has been focused on the firm level. In the following we first describe: (i) research methodologies used for macro guanxi research, including research design and measurement; and then (ii) summarize the research findings.

Research designs. The macro level research on guanxi has relied primarily on paper and pencil surveys of guanxi ties, guanxi practices, and their impact on firm performance or other firm-level variables (e.g., Gao, Xu, \& Yang, 2008; Gu, Hung, \& Tse, 2008; Peng \& Luo, 2000). For example, senior level managers of manufacturing firms in China filled out surveys about the existence or the utilization of various guanxi ties. The firm-level guanxi research has rarely used the network nomination method, hence yielding no network level data and limiting the analyses to the dyadic level. The second method, much less used, is the interview method (e.g., Buckley, Clegg, \& Tan, 2006; Guthrie, 1998; Nolan, 2010; Tan, Yang, \& Veliyath, 2009; Xin \& Pearce, 1996). Here researchers conducted extensive semi-structured interviews with respondents who had knowledge and experience with guanxi practices in China. Xin and Pearce (1996) asked respondents to recall personal connections and asked a serics of questions about guanxi practices as well as the importance and quality of the guanxi ties. Guthrie (1998) and Tan et al. (2009) incorporated a time dimension in their interview to illustrate how reliance on guanxi decreased as institutional reform deepened. 
Guanxi between organizations has been conceptualized either as the existence of guanxi ties between two organizations (e.g., Gao et al., 2008; Gu et al., 2008; Liu, Li, Tao, \& Wang, 2008; Su et al., 2009; Wu, 2008) or, more popularly, as guanxi strategies, namely, the extent to which guanxi ties are used for gaining competitive advantage (e.g., Li et al., 2008; Luo, 1997b; Luo \& Chen, 1997; Luo, Shenkar, \& Nyaw, 2002; Luo, Griffith, Liu, \& Shi, 2004; Park \& Luo, 2001; Peng \& Luo, 2000; Zhang \& Li, 2008). Guanxi ties, similar to the conceptions used in micro-level studies, refer to pre-existing particularistic ties between two boundary personnel from different firms. Two types of inter-firm guanxi ties figured prominently in macro empirical studies: business to business ties and business to government ties (e.g., Li, Yao, Sue-Chan, \& Xi, 2011; Luo et al., 2012; Park \& Luo, 2001; Peng \& Luo, 2000). Inter-firm guanxi ties are conceived primarily as part of the non-family, instrumental category (Luo, 1997b; Park \& Luo, 2001). The presence or absence of guanxi ties is mostly self-reported by company representatives (e.g., a top manager) with a few exceptions that used secondary data. Several studies (e.g., Chen, Jin, Long, \& Shao, 2010b; Chen et al., 2011 a; Wu, He, Lin, \& Wang, 2008) operationalized guanxi ties in terms of using the roles taken by top managers in business related associations and government related political entities.

Guanxi strategy is a dominant antecedent of firm performance. Guanxi strategy is defined as building and using personal connections to create and maintain competitive advantage and achieve superior performance (Luo, 2001; Luo et al., 2012; Park \& Luo, 2001; Peng \& Luo, 2000) but is often operationalized in terms of guanxi investment and guanxi utilization. Guanxi investment refers to the resources that the firm or boundary personnel use to cultivate personal relationships with individuals from other entities. Guanxi utilization, similar to guanxi practices (e.g., Guthrie, 1998), refers to the use of personal relationships to achieve organizational goals. Guanxi investment and utilization are measured mostly through perceptions of top managers (e.g., Li \& Zhang, 2007; Luo et al., 2002; Park \& Luo, 2001; Peng \& Luo, 2000 ) or through proxies such as sales force expenditures (Luo, 1997b; Luo \& Chen, 1997). One widely used scale of guanxi utilization (Peng \& Luo, 2000) asks respondents to rate, on a Likert scale, the extent to which top managers in their firm have utilized personal ties, networks, and connections with top managers at buyer firms, supplier firms, and competitor firms.

Research findings. The majority of macro-level research on guanxi has focused on how guanxi strategies affect firm performance. We refer readers to a comprehensive meta-analysis by Luo et al. (2012) on the effects of guanxi and firm financial and market performance. The following summaries, however, may provide additional insights by: (i) distinguishing between guanxi ties and guanxi strategies on firm performance and other outcomes; (ii) identifying contingencies in this relationship; (iii) paying more attention to the mediating mechanisms between guanxi and 
performance outcomes; and (iv) analyzing the antecedents of guanxi ties and guanxi practices.

Effects of guanxi ties and guanxi strategies on firm performance and other outcomes. Guanxi ties and strategies have consistently been found to have positive effects on market performance such as market share or growth rate compared with competitors, as well as financial performance such as return on assets (ROA) or on investment (ROI) (Luo et al., 2012). On the other hand, when distinguishing between business guanxi ties and political guanxi ties, accumulated research indicates that business ties often bring economic benefits to firms, whereas the effects of political ties are less consistent (Chen et al., 201 la; Guo \& Miller, 2010; Sheng, Zhou, \& Li, $2011)$.

In addition to financial and market performance, guanxi ties and/or strategy are found to have significant impact on market entry and international expansion (e.g., Ellis, 2000; Luo \& Liu, 2009; Tung \& Worm, 2001; Wong \& Ellis, 2002; Zhao \& $\mathrm{Hsu}, 2007$ ), entrepreneurship and venture capital investment (e.g., Batjargal \& Liu, 2004; Ellis, 2011; Peng, 2004), and organizational knowledge sharing and research and development (R\&D) (e.g., Buckley et al., 2006; Gao et al., 2008). Guanxi ties or strategies also led to the reduction of perceived relational risk (Liu et al., 2008), enhanced cooperative planning and problem solving between partner firms (Jiang \& Jin, 2008; Zhuang, Li, \& Cui, 2008), better knowledge transfer, sharing, or innovation (Buckley et al., 2006; Gao et al., 2008), enlarged industry entry or international trade partner identification (Ellis, 2000; Luo \& Liu, 2009), and higher chance of venture capital investment or joint venture partnership (Batjargal \& Liu, 2004; Wong \& Ellis, 2002). In contrast, a few other studies suggested a more complex effect of guanxi. For example, Zhuang et al. (2008) indicated that affective guanxi (i.e., family or friendship guanxi ties) was negatively related to perceived opportunism of the channel partners but instrumental guanxi ties were positively related. Chen, Tian, Ellinger, and Daugherty (2010a) found that the founder's affiliation with professional associations had a positive impact on decisions on research and development $(\mathrm{R} \& \mathrm{D})$ and intensity of $\mathrm{R} \& \mathrm{D}$ investment. However, if the founder sat on the People's Representative Committee or CPPCC Committee (Zheng Xie Wei Yuan 政协委员), the firm made less R\&D investment either because the political position might bring opportunities other than R\&D activities, or because guanxi connections actually hindered the firm's effort in R\&D activities.

Contingent factors on guanxi-firm performance. First, some firm characteristics moderate the effects of certain guanxi ties or guanxi strategies. The positive effect of guanxi ties on performance is stronger for small than for large firms (Peng \& Luo, 2000) and for foreign invested enterprises (FIEs) in the form of international joint venture rather than those of wholly-owned investments. It is also stronger for firms from countries with Chinese cultural roots, or with more length of operation in China 
than for firms without Chinese cultural roots, or with less length of operation (Luo, 1997b). However, Li et al. (2008) found that the benefit of guanxi utilization by foreign firms decreased at a certain threshold (i.e., an inverted U-shape relationship between ties and performance). Guanxi ties with government officials are more important for non-state owned firms than for state-owned firms (Peng \& Luo, 2000), and have greater positive effect on firm performance for new ventures in an environment of higher level dysfunctional competition (Li \& Zhang, 2007).

Second, some industry-related factors also moderate the effects of guanxi. Guanxi ties for firm performance are more crucial for service than for manufacturing industries and for firms in low rather than high growth industries (Peng \& Luo, 2000 ), less crucial in industries with higher competitive intensity or with lower structural uncertainty ( $\mathrm{Li}$ et al., 2008). Third, the type of firm performance qualifies the positive effect of guanxi strategies. For example, Park and Luo (2001) found that guanxi utilization achieved sales growth but not profit growth as guanxi cultivation needs financial resources. Similarly, Luo et al. (2002) found that guanxi strategy improved sales revenue but not cost reduction. Moreover, Sheng et al. (2011) found both institutional environment (e.g., government support and enforcement inefficiency) and market environment (e.g., technological turbulence and demand uncertainty) moderated the relationship between guanxi ties and firm financial performance. Lastly, over time, as market oriented reform deepens and institutional environment matures, the effect of guanxi ties or guanxi practices on performance diminishes (Guthrie, 1998; Li et al., 2008; Luo \& Chen, 1997; Tan et al., 2009).

Mediating variables between guanxi and firm performance. Recent studies have explored guanxi dynamics and their mediating effect between guanxi ties or guanxi practices on the one hand and firm performance on the other. For example, using a sample from Hong Kong firms, Wu (2008) discovered that guanxi ties increased information sharing between business partners, which in turn enhanced firm competitiveness. Chen et al. (2010a) found that guanxi facilitated collaboration between buyer and third-party logistic firms, resulting in better buyer performance. Gu et al. (2008) found that guanxi ties benefited a firm's distribution channels and its ability to scan and respond effectively to market changes. This ability, in turn, led to better market performance.

In a recent study of guanxi in supplier-distributor relations in China, Su et al. (2009) found that closer personal guanxi between the boundary spanners of the partners were more likely to lead to more interpersonal influence (reliance on personal/informal as opposed to impersonal/formal means of communication), which in turn increased relational satisfaction. Furthermore, the study found that guanxi oriented values of harmony, cooperation, and reciprocity enhanced the positive effect of guanxi ties on the use of interpersonal influence. Zhuang, Xi, and Tsang (2010) found that guanxi quality (in terms of social interactions and emotional closeness) between boundary spanning personnel of firms reduced conflict and 
improved cooperation between suppliers and department stores through the mediation of the exercise of non-coercive vs. coercive power. Studies of guanxi quality and inter-firm knowledge transfer showed that when the inter-firm guanxi was characterized by trust and communication, information sharing and knowledge transfer was more likely to occur (Ramasamy, Goh, \& Yeung, 2006; Shin et al., 2007).

Antecedents of guanxi ties and guanxi practices. Systematic studies on why guamxi is prevalent in Chinese business dealings are still scarce; but we can categorize the existing findings into society, industry, and firm levels of factors. Guanxi and guanxi practices are believed to originate from weak institutional support, such as the lack of legal protection and market mechanism (Lovett et al., 1999; Xin \& Pearce, 1996). In some specific industries, or during a specific period of industrial development, guanxi ties and practices are more prevalent (e.g., Peng \& Luo, 2000). Examples include a more volatile industrial environment, structural uncertainty and instability, industrial growth, and competitive pressure (Jiang, Jin, Jiao, \& Ma, 2009; Luo, 2003). At the organizational level, factors that promote guanxi reliance and guanxi strategies include non-state-owned, small, newly founded firms, or firms located in less open economic regions, with limited technology skills, managerial capabilities, or other limited resources (Park \& Luo, 2001; Zhou et al., 2003).

In summary, most macro-level studies are based on the premise that guanxi ties are a valuable resource or efficient governing mechanism to the organization and, as a result, have positive effects on organizational level performance. There are a number of challenges to this premise. First, these studies have not illuminated the underlying mechanisms that motivate or inhibit utilization of personal guanxi for the organization's welfare. Second, they fail to address potential issues of guanxi owners pursuing their individual self-interests at the organization's cost (Chen \& Chen, 2009; Coff, 1999; Dunfee \& Warren, 2001). As well, a simplistic guanxi-performance view may overlook possible alternative motives of guanxi making and investment. Third, it is possible that only those well performed firms have resources to invest in guanxi, implying a reverse causal relationship between guanxi and performance. Lastly, guanxi research at macro level still faces measurement challenges. Most macro studies conceive guanxi in terms of guanxiquality or strength, but operationalize guanxi as either guanxi strategies or the number of guanxi ties. Clearly, guanxi stratcgy (Peng \& Luo, 2000) should not be used to measure guanxi quality because guanxi strategies can be targeted at weak or strong guanxi ties. The number of external guanxi ties of a firm may depend on which focal internal parties are included. For example, beyond those of the top management team, do external guanxi ties of lower level managers and the boundary spanners of a firm count? Furthermore, all guanxi ties are not equal in strength: family ties may be stronger than non-family guanxi and national level congressional representatives (Ren Da Dai Biao 人大代表) may have stronger political connections than county representatives. 


\section{Empirical Research on Guanxi Practices and Ethics}

From moral and ethical perspectives (Dunfee \& Warren, 2001), certain guanxi practices are problematic to the extent that they hurt the interests of the third party or the larger community, or violate principles of justice and fairness. Empirical research that explores these issues about guanxi has recently started to emerge. Warren et al. (2004) studied the paradoxical (helpful and harmful) consequences of guanxi practices to the guanxi actor, the organization, and the larger Chinese community. Participants were asked to evaluate given guanxi scenarios as well as provide guanxi scenarios. The majority of respondents rated guanxi practices as always helpful to the focal actor, but sometimes helpful and sometimes harmful to the organization, and most times harmful to the community. In providing guanxi scenarios, the respondents viewed guanxi practices as a double-edged sword. On the one hand, guanxi practices may help both the individual guanxi actor and the organization and the community. On the other hand, reinforcing the first finding, the participants provided vivid examples of how guanxi practices benefited individual users but undermined merit- and product-based competitiveness in the organization and damaged the economic, legal, and ethical institutions of the larger Chinese society. The most telling finding is that as many as 7 percent of the 195 respondents could not see any form of guanxi that would benefit the community. The authors warned of the coercive aspects of guanxi practices, namely, individuals and organizations who used guanxi because they lacked alternative, legitimate means of achieving their objectives or of protecting their legitimate interests.

In contrast to Western normative theories of morality, Tan and Snell (2002: 362) argued that, according to the Chinese moral tradition, 'moral behaviour varies according to a person's role, position, and relationship with other role-players in a highly differentiated and hierarchical social nexus'. The authors constructed workplace ethical dilemmas between Confucian relational, role-specific virtues such as xin 信 (peer trust), ren 任 (benevolence), xiao 孝 (filial piety), and zhong 忠 (loyalty) and modernist morality dictated by organizational rationality such as firing for poor performance and truth telling about misconduct of peers and superiors. They found that Singaporean Chinese were significantly more lenient than their expatriate counterparts in cases of trust and loyalty, in which the protagonist decided to protect peers and assume blame for the boss. These results suggest that in making moral and ethical judgments, Singaporean Chinese pay more attention to contextualized information including the role, intention, obligations, and consequences of all relevant parties, especially those of the actor. However, they still rated such behaviour as unethical, suggesting that 'guanxi morality among Singaporean Chinese managers persists in a vestigial form that may readily be overridden by other considerations' (Tan \& Snell, 2002: 380).

Ho and Redfern (2010) replicated Tan and Snell's (2002) study but added the assessment of moral development on the basis of subjects' justifications for their 
ethicality evaluation. Content analyses were conducted of the justifications, which categorized the rationales and ranked the categories according to Kohlberg's (1969) six stages of moral development such that traditional guanxi rationales represent lower levels of moral development while universal rationales represent higher levels of moral development. They found that among $165 \mathrm{Hong}$ Kong bank managers, those who appealed to guanxi moral rationales were more lenient in their unethicality evaluations than those who appealed to universal rationales.

Su et al. (2003) investigated the relationship between guanxi orientation (defined as emphasis on interdependence and reciprocity in business relationships) and the cognitive moral development of purchasing managers from state-owned, privatelyowned, collectively-owned, and China-foreign joint venture business firms. They found that, although the purchasing managers of private and collective firms scored higher in guanxi orientation than those of state-owned and joint venture firms, there were no group differences in the level of cognitive moral development across different ownership types. More importantly, contrary to Ho and Redfern's (2010) finding, the cognitive moral development was not significantly related to guanxi orientation whereas time spent in the purchasing profession and educational level was.

\section{Cross-cultural Research on Guanxi}

Earlier we discussed the perspective of Confucian relationalism and pointed out that its effect on organizational behaviour has often been explored in contrast to Western management theories. This section is therefore devoted to cross-cultural research on guanxi, focusing on: (i) the importance of personal relationships; (ii) the effect of strong and weak ties; and (iii) the changing role of guanxi in China.

The importance of personal relationships. One stream of cross-cultural research on guanxi focuses primarily on the differences between Chinese and Western cultures in the importance of personal relationships in business and management decision making. Western negotiators, for example, attempt to adapt to the Chinese culture by primarily recognizing the importance of personal relationships whereas Chinese negotiators attempt to adapt to the Western culture by following rational and professional protocols (Sheer \& Chen, 2003). One interesting exception is the study by Sue-Chan and Dasborough (2006) who found that in selection decisions, Australian participants favoured their friend, who was an average performer and far inferior to other candidates, while Hong Kong Chinese did not:

Comparative research also found evidence that personal relationships are more important in China guanxi marketing than in most Western relationship marketing. The concept of relationship marketing emphasizes relationship-oriented rather than transaction-oriented inter-firm interactions (Berry, 1983, 2002; Dwyer, Schurr, \& Oh, 1987; Morgan \& Hunt, 1994). Similarly, Wang (2007) emphasized that the 
Chinese business relationship was often the outcome of personal relationships whercas relationship marketing is rooted in impersonal trust building practices, such as the implementation of written agreement and legal contracts. Zhuang and $\mathrm{Xi}$ (2003) compared Chinese guanxi marketing with Western relationship marketing in aspects such as objectives, bases, principle, media, behaviour, and morality.

Research by Chua et al. (2009) provided supporting evidence that, compared to their American counterparts, Chinese managers were more likely to use familial norms of guanxi in their professional relationships. Social affect and cognition were more intertwined in Chinese than in American professional relationships. Furthermore, economic dependence and affect based trust was positively correlated in Chinese professional ties but negatively correlated in American professional ties. The authors further found that there were significantly more kin-like relationships in Chinese than American social networks. Chinese were also less likely to regard mentor figures as friends than were Americans. Similarly, Morris et al. (2008) proposed that Chinese workplace relations were modelled on the familial norms of filial duty. Using egocentric network data and comparing network content and structure, the authors found that Chinese bank employees were more likely to direct their instrumental exchanges with formal superiors (as opposed to peers) than employees from America, Germany or Spain. They also found that Americans' network ties lasted the shortest; Germans had the least affective closeness in their instrumental ties, and Spanish friendship ties lasted the longest. The Spanish workers also spent the most time talking to their colleagues on non-job required topics.

The effects of strong and weak ties. In contrast to Western research that highlights the advantage of weak ties and structural holes of social networks in obtaining employment and advancing career (Burt, 1992; Granovetter, 1973), research on Chinese guanxi networks found that the Chinese relied on helpers (direct or indirect) with whom they have strong rather than weak ties to find and change jobs (Bian, 1997; Bian \& Ang, 1997). Giles, Park, and Cai's (2006) study of dislocated urban workers found that re-employment was positively correlated with the number of same generation relatives in the same city for both men and women. Research also shows that managers who build a professional network consisting of strong ties are more successful in their career achievement than those who build a network of weak ties (in which they assume the role of a broker) (Xiao \& Tsui, 2007). In explaining the advantage of dense networks of strong ties as opposed to loose networks with many structural holes in Chinese organizations, Xiao and Tsui (2007) appealed to the high-commitment culture of Chinese organizations, as well as the collectivist values of the Chinese national culture. Bian and Ang (1997) made similar cultural arguments by showing that even though Singapore has a well-established labour market and a modern system of HRM, societal and organizational orientation toward relationships led job changers to seek help from strong tie rather than weak tie contacts. 
The changing role of guanxi in the Chinese culture. Relating to the culture perspective is the debate among guanxi researchers on the increasing or decreasing role of guanxi in Chinese society. On one side of the debate, the prevalence of guanxi practices is primarily seen as resulting from the lack, or imperfection, of legal and regulatory institutions in China (Guthrie, 1998, 2002; Luo, 1997a; Xin \& Pearce, 1996). With market oriented economic reform and the establishment of market institutions, reliance on guanxi, especially its corrosive aspects, will generally decrease or shift from being the primary to the complementary (Khatri et al., 2006; Tan et al., 2009; Yi \& Ellis, 2000; Zhang \& Keh, 2009). There has been supporting evidence for this point of view. For example, comparisons of Hong Kong and mainland Chinese managers found that culture played only a minor role in guanxi existence and utilization (Luk, Yau, Sin, Tse, Chow, \& Lee, 2008) but executives viewed guanxi use as more costly, time consuming, and more likely to be perceived as being corrupt than mainland Chinese executives did (Yi \& Ellis, 2000). Tan et al.'s (2009) case studies of Chinese small and medium enterprises in western provinces in China revealed that personal guanxi practices targeted at government and businesses connections as well as personal trust associated with such practices became less critical as China transitioned from a centrally planned to a market economy.

The other side of the debate argues that guanxi is deeply rooted in Chinese culture as it has been formed and reinforced over two thousand years of Chinese feudal society (Fei, 1992/1947). According to the cultural view, the guanxi phenomenon is by no means transitory. Boisot and Child (1996) even argued that Chinese tradition and culture would shape reform to a direction of clan-like network capitalism, where guanxi might become the label of the Chinese economy. Yang (2002) took a similar view that some aspects of guanxi might decline as China entered capitalism but guanxi would adapt to the market economy and find new circumstances in which to flourish. There has been some supporting evidence for this point of view as well. Based on his field studies on entrepreneurs from private companies in Xiamen, China, Wank $(1999,2002)$ found that guanxi was still playing a significant role in economic activities after China's reform. Nolan's (2010) in-depth interviews with 26 senior managers from Western banks who had experience and knowledge in corporate governance reform in Chinese banks, concluded that a guanxi culture persisted in the external and internal environment of the Chinese banking industry, thwarting recent reforms. Studies on other Asian market economies, such as Singapore and Taiwan, show that personal guanxi remains critical in business and employment relations (Bian \& Ang, 1997; Hsing, 1998). Chen et al. (2011a) found that even though the economic benefits were not present for private domestic firms that establish political guanxi ties with the government, the number of business owners who built such connections actually increased significantly over the past 20 years. 
So what do we learn from the debate about guanxi and the seemingly mixed or even contradictory findings in Chinese guanxi research? First, guanxi practices may depend to a large extent on the actor's perception of the importance and the necessity of using guanxi for a given transaction. Second, guanxi reliance may decrease in some areas but persist or even increase in others. Third, not all guanxi users are rational in that they calculate the costs and benefits of guanxi expenditure vs. alternative means. Guanxi use can therefore persist or increase due to cultural habits or the psychological safety that guanxi ties may provide. Based on this discussion, research that addresses the increasing or decreasing role of guanxi should include the time horizon in its design. Furthermore, to truly assess if any guanxi phenomenon under study changes over time, the phenomenon itself needs to be held stable, be it a guanxi actor characteristic, guanxi practice, or guanxi outcome. In this way research can demonstrate whether the role of guanxi with regard to a particular type of transactions by the same type of actors has decreased, increased, or remained the same over time (e.g., Luo et al., 2012; Tan et al., 2009).

Methodological, situational, and psychological factors aside, the fundamental question, whether the prominence of guanxi reliance is ingrained in the Chinese culture or in the institutional arrangement has no straightforward answers. First, culture is part of the institutional environment of a society albeit soft and somewhat informal (DiMaggio \& Powell, 1983). While culture is evolving and adaptive to changes in society, it is not merely a product of hard institutional arrangements but part of the pre-existing environment in which institutional reforms are initiated and implemented. Second, the various elements of institutional environment are not always well-aligned or move in tandem. Culture may constrain, facilitate, or yield to an institutional reform depending on complex factors, such as the actual or expected consequences of the reform, the major stakeholders affected, and the challenge presented to the existing prevailing cultural values and norms. The diverse and even conflicting research evidence regarding the increasing and decreasing role of guanxi practices in our view partly reflects the dynamic relationship between cultural and institutional changes in China. We therefore recommend researchers study the reciprocal influence and the interaction of culture and formal institutions regarding guanxi practices of individuals, groups, and organizations.

\section{DISGUSSION: DIREGTIONS FOR FUTURE RESEARCH}

So far we have reviewed the conceptual definitions of guanxi, the major perspectives and theories used in guiding guanxi research, and the empirical research on guanxi. Along the way, we also offer some suggestions and recommendations as to how to advance research on guanxi. In the following, we highlight areas that have been neglected and suggest new promising directions for future guanxi research. 


\section{Areas of Neglect}

There are a few areas of glaring neglect in guanxi research. First, guanxi or social networking research on groups in organizations is almost completely absent. As can be seen from Table 1, only one study at the group level was cited in this paper. Hence, we know little about how work groups composed of close or distant guanxi ties differ in terms of group dynamics and group effectiveness or how dyadic intergroup guanxi ties and practices affect group performance. This is an entirely virgin territory with great promise for future research.

Second, although there are some studies of ego-centric networks of individual persons (Bian, 1997; Chua et al., 2009; Morris et al., 2008; Xiao \& Tsui, 2007), most guanxi research has not examined the effects of structural characteristics such as size, centrality, and homophily. This is a serious gap especially for inter-firm guanxi research as much of the guanxi-firm performance link was based on dyadic guanxi ties without structural characteristics at the network level. The structure of guanxi ties with other organizations needs to be taken into consideration. For example, if all the top managers have guanxi ties with the same set of external entities, or the same managers share a dense network, guanxi's effect on firm performance might be reversed because of the potential small world problem (Uzzi \& Spiro, 2005). Including structural features can also help alleviate possible biases of the same source in survey studies.

Third, much research has been focused on how various guanxi ties affect outcomes. Process models of guanxi use are largely conceptual, yet to be tested. There are many interesting and challenging research topics in this area at both the interpersonal and inter-firm levels, some of which we will elaborate in the following sections. Lastly, there is virtually no research on the distinction and the interface between informal guanxi and the formal organization (Bu \& Roy, 2008; Nolan, 2010; Parnell, 2005). At the interpersonal level, research has examined how social ties and outside work exchanges between formal supervisor-subordinate relationships. However, at the network level of a focal group or firm, to what extent does the informal guanxi network overlap with the formal organizational chart and do the two complement or counter each other to affect organizational processes and outcomes? Firm level research could reveal the interface dynamics of informal social net of the top managers and the formal net of institutional ties.

\section{Need for Conceptual Specificity of Guanxi Constructs}

Clarification and specification of guanxi constructs are needed. Our review of the guanxi literature has revealed three sets of guanxi concepts: guanxi types (e.g., preexisting guanxi bases or current guanxi ties), guanxi quality (e.g., tie strength, tie closeness, or LMG), and guanxi practices (activities or strategies of developing or utilization of guanxi). It is no longer acceptable to use the umbrella term guanxi in a particular study without specifying what aspect(s) of guanxi are targeted and at what 
levels of analyses. Specifying the content aspects and the levels of analyses at the minimum prevents misunderstanding and cross-talking but more importantly helps accumulate and advance knowledge in this field. Take firm level guanxi for example. It can refer either to guanxi ties per se or strategies of using such guanxi ties for achieving organizational outcomes; firm guanxi ties can be further differentiated from personal guanxi ties established by managers or boundary spanning professionals and from official institutional guanxi ties such as political appointments or professional ties through joint membership of business associations. Specifying the nature and the level of guanxi ties for macro firm level research is essential for generating valid results about the importance and functionality of guanxi.

\section{Additional Avenues for Future Research}

Cross-domain guanxi research. What is both fascinating and challenging about Chinese guanxi is that it permits if not facilitates interpenetration between the private and the public domains. By private we mean the family and kin, and the personal friendship relations that are more associated with affectivity. By public we mean organizational, business, and professional relations, which are more associated with rational instrumentality. Guanxi researchers, as we have reviewed, have done much to categorize and differentiate the two types of guanxi. What is lacking is systematical theorization and research on the interface and the interaction between the two domains, as well as their fluidity and mixture. For example, how personal relations are used for the accomplishment of company performance, or how professional and official relationships are exploited for the benefit of personal interests. The mixed domain of the private and the public may better reflect Chinese guanxi dynamics than either the private or the public domain separately.

The dynamic processes of guanxi practices. Most guanxi research has been rather static in that it neglects the paradoxical and contradictory effects of guanxi ties and guanxi strategies as well as the processes of guanxi development and utilization. Future research could adopt dynamic perspectives that embrace complexity (Stacey, Griffin, \& Shaw, 2000), balance and integrate paradoxical guanxi phenomena (Chen, 2008; Li, 2008).

At the individual level, research can examine the dynamics of how the characteristics of guanxi actors, the ego or the alter, may affect the processes and outcomes of guanxi practices. Systematic research may shed light on the effect of the human capital of the individual guanxi actor on his or her social capital and how they interact to affect social interaction and social mobility. Another fruitful topic is the role of the intermediary in building and using interpersonal guanxi ties (Bian, 1997; Chen \& Chen, 2004). The intermediary is the party that is connected to two different parties, say Parties A and B, who are themselves not connected to each 
other. The importance of the intermediary and the non-transitivity of close relationships may be a salient characteristic of the Chinese society, which could explain the persistence of some exclusive close guanxi ties and networks in China and help explain why people are constantly building guanxi with those who seemingly have no relevance in their life circle.

At the firm level, previous research has established that personal guanxi ties affect firm performance yet it remains a black box in regards to what ways and under what conditions personal connections are used to improve firm level performance (Tsang, 1998; Zhang \& Zhang, 2006). Researchers need to identify various social and organizational mechanisms through which personal guanxi ties are used for the accomplishment of firm level results (Chen \& Chen, 2012; Su et al., 2009). One also can investigate under what incentive and appraisal system individual guanxi owners are willing to use their guanxi ties for organizational purposes (Balkundi \& Harrison, 2006). Organizational transferability of personal guanxi may also depend on the interlocking of individual employees' personal network. A firm's internal guanxi networks as a whole could maintain some personal guanxi ties even if the original guanxi owners have left the firm. These guanxi ties of remaining employees, though not formalized into the routines of business operation, are collective and unique in nature and hard to imitate, thus bringing sustainable competitive advantage for the firm. Researchers can explore the dynamics of the development and transference of personal guanxi networks (Hoegl, Parboteeah, \& Munson, 2003) by using an evolutionary lens as proposed by Powell, White, Koput, and Owen-Smith (2005).

Costs and benefits of guanxi characteristics and practices. Many guanxi characteristics and practices are like double-edged swords in bringing about both positive and negative outcomes. Past research however has been polarized in that some focus on the positive whereas others on the negative, with the majority documenting the positive. Future research could provide a more balanced and comprehensive understanding of the function and consequences of guanxi (e.g., Han \& Altman, 2009). We encourage studies that test the double-edged hypothesis of guanxi function, simultaneously examining the positive and the negative consequences of guanxi characteristics and practices predicted by theories that explicate the conditions that bring out or facilitate such results (Fan, 2002b; Standifird \& Marshall, 2000; Su \& Littlefield, 2001). Future research should also identify variables that are likely to moderate the relationship between the guanxi network and its associated advantages.

Multi-theoretical and multi-level perspectives. We have identified three major theoretical perspectives: the ego-pragmatic, the community ethical, and the Confucian relational perspectives. Within and among these perspectives, a great variety of theories have been used to study the guanxi phenomenon. The field of guanxi research is becoming more mature and the benefits of research integrating different theoretical perspectives are being seen. Using the well-known analogy of feeling for the 
truth of an elephant from a single perspective, we believe while each perspective generates bits and pieces of the guanxi elephant, what is needed is the integration of multiple perspectives to gain a more accurate and complete picture.

One program of research that has the potential for integrating different perspectives is to analyze when personal guanxi ties become organizational social capital, the conditions under which such transference is blocked or facilitated, and the consequence of the transference to both the individual guanxi owner and the organization. Such a research program is situated in the cross sections of multiple perspectives and theories, such as personal vs. organizational social capital, and traditional role specific ethics vs. modern global ethics. Chen and Chen's (2012) multilevel integrative model shows how such a research program can be pursued. The authors used social capital theory to explain the motives behind guanxi development, and social exchange theory to explicate the mechanisms involved in guanxi dynamics that facilitates the transference of interpersonal guanxi to interfirm guanxi.

By multi-level theory and research we focus on its theoretical rather than methodological aspects. For methodological considerations we refer readers to our suggestions in the sections of research methodologies and summary and critique part at the end of our review for each area of studies. We outline a number of research topics that could benefit from the multi-level approach. First is the top down cascading effect of guanxi ties and practices. Do guanxi ties and practices of higher level organizational members affect those of the lower levels, or do the guanxi variables at the higher level of the organization affect outcomes of the lower levels? Second is the bottom up transference process as we discussed above in the integration of multi-theory perspectives? The research on social capital transference from the individual to the organization clearly requires multi-level theorizing and design. It is necessary to identify those 'micro mechanisms' of transference (Tsang, 1998; Zhang \& Zhang, 2006). Furthermore, researchers could explore factors across different levels of the organization that may block or facilitate this 'social capital transferring' process. For example, the role of organizational and group levels of culture, climate, norms, leadership, and justice and the individual level factors such as organizational commitment, job satisfaction, and trust in management. Third, the functionality or the positive or negative consequences of guanxi practices clearly depend on the level of analyses. Individual and group level researchers have begun to tackle this issue by means of a cross-level approach. The work of Chen, Friedman, Yu, and Sun (2011b) is a good example of how multiple level perspectives offer a more nuanced understanding of guanxi practices. The multiple level perspective and design allow the researchers to examine the paradoxical effect of how guanxi practice can benefit subunits at the expense of the superordinate units. At the firm level, it is not clear how guanxi strategies help or harm the industry and the community in which the firms operate. Cross-level research would make a major contribution to existing firm level research. 


\section{CONGLUSION}

The past three decades have witnessed a great surge of scholarly interest in studying Chinese guanxi. However, research in this area has been highly heterogeneous, if not fragmented, in conceptualizing and operationalizing guanxi, and in examining its antecedents, processes, outcomes and boundary conditions. We sought to provide a state of scientific review by analyzing, synthesizing, and integrating this large body of literature. We further identified gaps and potential for advancing guanxi research through multi-perspective and multi-level theorizing and examination. In doing so, we hope that guanxi theories and research will not only help illuminate the complexity of guanxi in Chinese organizations and societies but also that of human relations in the rest of the world.

\section{NOTES}

We would like to express our appreciation to Jingzhou Pan for his assistance with creating Table 1 of the paper, and to the Action Editor, Larry Farh, and two anonymous reviewers for their constructive comments on the earlier drafts of the paper.

\section{REFERENCES}

Alston, J. P. 1989. Wa, guanxi, and inhwa: Managerial principles in Japan, China, and Korea. Business Horizons, 32(2): 26-31.

Aryce, S., \& Chen, Z. X. 2006. Leader-member exchange in a Chinese context: Antecedents, the mediating role of psychological empowerment and outcomes. Joumal of Business Research, 59(7): 793-801.

Balkundi, P., \& Harrison, D. 2006. Ties, leaders, and time in teams: Strong inference about networks tructure's effects on team viability and performance. Academy of Management Joumal, 49(1): 49-68.

Barncy, J. 1991. Firm resources and sustained competitive advantage. Journal of Management, 17(1): 99-120.

Batjargal, B., \& Liu, M. 2004. Entrepreneurs' access to private equity in China: The role of social capital. Organization Science, 15(2): 159-173.

Bell, D. 2000. Guanxi: A nesting of groups. Current Anthropology, 41(1): 132-138.

Berry, L. 1983. Relationship marketing. In L. Berry, G. L. Shostack \& R. Upah (Eds.), Emerging perspectives on services marketing: 25-28. Chicago, IL: American Marketing Association.

Berry, L. 2002. Relationship marketing of services - Perspectives from 1983 and 2000.Journal of Relationship Marketing, 1(1): 59-77.

Bian, Y. 1997. Bringing strong ties back in: Indirect ties, network bridges, and job searches in China. American Sociological Revieze, 62(3): 366-385.

Bian, Y., \& Ang, S. 1997. Guanxi networks and job mobility in China and Singapore. Social Forces, 75(3): 981-1005.

Blau, P. M. 1964. Exchange and pozer in social life. New York: Wiley.

Blau, P. M., \& Duncan, O. D. 1967. The American occupational structure. New York: Wiley. Boisot, M., \& Child, J. 1996. From fiefs to clans and network capitalism: Explaining China's emerging economic order. Administrative Science Quarterly, 41(4): 600-628.

Bond, M. H., \& Hwang, K. K. 1986. The social psychology of Chinese people. In M. H. Bond (Ed.), The psychology of the Chinese people: 213-266. Hong Kong: Oxford University Press.

Brass, D. J. 1995. A social network perspective on human resources management. Research in Personnel and Human Resources Management, 13: 39-79. 
Bu, N., \& Roy, J.-P. 2008. Chinese managers' career success networks: The impact of key tie characteristics on structure and interaction practice. International Joumal of Human Resource Management, 19(6): 1088-1107.

Buckley, P. J., Clegg, J., \& Tan, H. 2006. Cultural awareness in knowledge transfer to China - the role of guanti and mianzi. Journal of World Business, 41(3): 275-288.

Burt, R. S. 1992. Structural holes: The social structure of competition. Cambridge, MA: Harvard University Press.

Chai, S.-K., \& Rhec, M. 2010. Confucian capitalism and the paradox of closure and structural holes in East Asian firms. Management and Organization Revieze, 6(1): 5-29.

Chen, C. C., \& Chen, X.-P. 2009. Negative externalities of close guanxi within organizations. Asia Pacific Joumal of Management, 26(1): 37-53.

Chen, C. G., Chen, Y.-R., \& Xin, K. 2004. Guanxi practices and trust in management: A procedural justice perspective. Organization Science, 15(2): 200-209.

Chen, C. C., \& Farh, J. L. 2010. Developments in understanding Chinese leadership: Paternalism and its elaborations, moderations, and alternatives. In M. Bond (Ed.), Oxford handbook of Chinese psychology: 599-622. Oxford: Oxford University Press.

Chen, H., Tian, Y., Ellinger, A. E., \& Daugherty, P. J. 2010a. Managing logistics outsourcing relationships: An empirical investigation in China. Journal of Business Logistics, 31(2): 279-299.

Chen, M.-J. 2008. Reconceptualizing the competition - cooperation relationship : A transparadox perspective. Journal of Management Inquiry, 17(4): 288-304.

Chen, N. Y., \& Tjosvold, D. 2006. Participative leadership by American and Chinese managers in China: The role of relationships. Journal of Management Studies, 43(8): 17271752.

Chen, N. Y., \& Tjosvold, D. 2007. Guanxi and leader member relationships between American managers and Chinese employees: Open-minded dialogue as mediator. Asia Pacific Joumal of Management, 24(2): 171-189.

Chen, S. Y. (陈爽英), Jin, R. T. (井润田), Long, X. N. (龙小宁), \& Shao, Y. F. (邵云飞) 2010b. An empirical study on the impact of guanxi capital of private entrepreneurs on R\&D decision. Management World (管理世界), 196(1): 88-97. (in Chinese.)

Chen, X.-P., \& Chen, C. C. 2004. On the intricacies of the Chinese guanxi: A process model of guanxi development. Asia Pacific Joumal of Management, 21(3): 305-324.

Chen, X.P., \& Chen, C. C. 2012. Chinese guanxi: The good, the bad, and the controversial. In $\mathrm{X}$. Huang \& M. H. Bond (Eds.), The handbook of Chinese organizational behaviour: Integrating theory, research and practice: 415-435. Cheltenham: Edward Elgar.

Chen, X.-P., Li, X., \& Liang, X. 201 la. Why do business leaders pursue political connections in China? Economic benefits or psychological placebo? Academy of Management Conference paper.

Chen, X.-P., \& Peng, S. 2008. Guanxi dynamics: Shifts in the closeness of ties between Chinese coworkers. Management and Organization Revieze, 4(1): 63-80.

Chen, Y., Friedman, R., Yu, E., Fang, W., \& Lu, X. 2009. Supervisor-subordinate guanxi: Developing a three-dimensional model and scale. Management and Organization Revieze, 5(3): 375399.

Chen, Y., Friedman, R., Yu, E., \& Sun, F. $201 \mathrm{lb}$. Examining the positive and negative effects of guanxi practices: A multi-level analysis of guanxi practices and procedural justice perceptions. Asia Pacific Joumal of Management, 28(4): 715-735.

Chow, I. H.-S., \& Ng, I. 2004. The characteristics of Chinese personal ties (guanxi): Evidence from Hong Kong. Organization Studies, 25(7): 1075-1093.

Chua, R. Y. J., Morris, M. W., \& Ingram, P. 2009. Guanxi vs. networking: Distinctive configurations of affect- and cognition-based trust in the networks of Chinese vs. American managers. Jourmal of Intemational Business Studies, 40(3): 490-508.

Coase, R. H. 1937. The nature of the firm. Economica, New Series, 4(16): 386-405.

Coff, R. W. 1999. When competitive advantage doesn't lead to performance: The resource-based view and stakeholder bargaining power. Organization Science, 10(2): 119-133.

Confucius. 1915. The ethics of Confucius. New York: Putnam.

Davies, H., Leung, T. K. P., Luk, S. T. K., \& Wong, Y.-H. 1995. The benefits of 'guanxi': The value of relationships in developing the Chinese market. Industrial Marketing Management, 24(3): $207-214$. 
Dawes, R. M. 1980. Social dilemmas. Annual Revieze of Psychology, 31: 169-193.

De George, R. T. 1993. Competing zwith integrity. New York: Oxford University Press.

DiMaggio, P., \& Powell, W. 1983. The iron cage revisited: Institutional isomorphism and collective rationality in organizational fields. American Sociological Revieze, 48(2): 147160 .

Donaldson, T. 1996. Values in tension: Ethics away from home. Harvard Business Revieze, September-October: 48-62.

Dunfee, T. W., \& Warren, D. E. 2001. Is guanxi ethical? A normative analysis of doing business in China. Journal of Business Ethics, 32(3): 191-204.

Dwyer, F. R., Schurr, P. F., \& Oh, S. 1987. Developing buyer-seller relationships. Journal of Marketing, 51(2): 11-27.

Ellis, P. D. 2000. Social ties and foreign market entry. Joumal of International Business Studies, 31(3): 443-469.

Ellis, P. D. 2011. Social ties and international entrepreneurship: Opportunities and constraints affecting firm internationalization. Journal of International Business Studies, 42(1): 99-127.

Fairhurst, G. T., \& Chandler, T. A. 1989. Social structure in leader-member interaction. Communication Monographs, 56(3): 215-239.

Fan, Y. 2002a. Ganxi's consequences: Personal gains at social cost. Journal of Business Ethics, 38(4): $371-380$.

Fan, Y. 2002b. Questioning guanxi: Definition, classification and implications. International Business Review, 11(5): 543-561.

Farh, J.-L., \& Cheng, B.-S. 2000. A cultural analysis of paternalistic leadership in Chinese organizations. In J. T. Li, E. Tsui \& E. Weldon (Eds.), Management and organizations in the Chinese context: 84-127. London: Macmillan Press Ltd.

Farh, J.-L., Tsui, A. S., Xin, K., \& Cheng, B.-S. 1998. The influence of relational demography and guanxi: The Chinese case. Organization Science, 9(4): 471-488.

Fei, H. 1992/1947. From the soil, the foundations of Chinese society. Berkeley: University of California Press.

Fiske, A. P. 1992. The four elementary forms of sociality: Framework for a unified theory of social relations. Psychological Revieze, 99(4): 689-723.

Fu, P. P., Tsui, A. S., \& Dess, G. G. 2006. The dynamics of guanxi in Chinese high-tech firms: Implications for knowledge management and decision making. Management Intemational Revieze, 46(3): 277-305.

Gao, S., Xu, K., \& Yang, J. 2008. Managerial ties, absorptive capacity, and innovation. Asia Pacific Joumal of Management, 25(3): 395-412.

Giles, J., Park, A., \& Cai, F. 2006. Reemployment of dislocated workers in urban China: The roles of information and incentives. Joumal of Comparative Economics, 34(3): 582607.

Graen, G. B., \& Uhl-Bien, M. 1995. Relationship-based approach to leadership: Development of leader-member exchange (LMX) theory of leadership over 25 years: Applying a multi-level multi-domain perspective. The Leadership Quarterly, 6(2): 219-247.

Granovetter, M. 1973. The strength of weak ties. American Joumal of Sociology, 78(6): 13601380.

Gu, F. F., Hung, K., \& Tse, D. K. 2008. When does guanxi matter? Issues of capitalization and its dark sides. Journal of Marketing, 72(4): 12-28.

Guo, C., \& Miller, J. K. 2010. Guanxi dynamics and entrepreneurial firm creation and development in China. Management and Organization Review, 6(2): 267-292.

Guthrie, D. 1998. The declining significance of guanxi in China's economic transition. China Quarterly, 154: 254-282.

Guthrie, D. 2002. Information asymmetries and the problems of perception: The significance of structural position in assessing the importance of guanri in China. In T. Gold, D. Guthrie \& D. Wank (Eds.), Social connections in China: Institutions, culture and the changing nature of guanxi: 37-56. Cambridge, MA: Cambridge University Press.

Hackett, R. D., Farh, J.-L., Song, L. J., \& Lapierre, L. M. 2003. LMX and organizational citizenship behavior: Examining the links within and across Western and Chinese samples. In G. Graen (Ed.), Dealing with diversity: LMX leadership, 1: 219-263. Greenwich, CT: Information Age. 
Han, Y., \& Altman, Y. 2009. Supervisor and subordinate guanxi: A grounded investigation in the People's Republic of China. Journal of Business Ethics, 88(1): 91-104.

He, W., Qiao, Q., \& Wei, K.-K. 2009. Social relationship and its role in knowledge management systems usage. Information \& Management, 46(3): 175-180.

Hitt, M. A., Beamish, P. W., Jackson, S. E., \& Mathieu, J. E. 2007. Building theoretical and empirical bridges across levels: Multilevel research in management. Academy of Management Journal, 50(6): 1385-1399.

Ho, C., \& Redfern, K. A. 2010. Consideration of the role of guanxi in the ethical judgments of Chinese managers. Joumal of Business Ethics, 96(2): 207-221.

Ho, D. Y. F. 1998. Interpersonal relationships and relationship dominance: An analysis based on methodological relationalism. Asian Journal of Psychology, 1(1): 1-16.

Ho, D. Y. F. (何友晖) 1999. Interpersonal affect and Ren Qing. Indigenous Psychological Research (本土心理学研究), 12: 181-187. (in Chinese.)

Hoegl, M., Parboteeah, K. P., \& Munson, C. L. 2003. Team-level antecedents of individuals' knowledge networks. Decision Sciences, 34(4): 741-770.

Hom, P. W., \& Xiao, Z. 201 l. Embedding social networks: How guanxi ties reinforce Chinese employees' retention. Organizational Behavior and Human Decision Processes, $116(2): 188-202$.

Homans, G. C. 1958. Social behavior as exchange. American Joumal of Sociology, 63(6): $597-606$

Hsing, Y.-T. 1998. Making capitalism in China: The Taizvan connection. New York: Oxford University Press.

Hsu, F. L. K. 1963. Clan, caste and club. New York, NY: Van Nostrand Reinhold Co.

Hu, H.-H., Hsu, W.-L., \& Cheng, B.-S. 2004. Rewards allocation decisions of Chinese managers: Influence of employee categorization and allocation context. Asian Joumal of Social Psychology, 7(2): 221-232.

Hui, C., Law, K. S., \& Chen, Z. X. 1999. A structural equation model of the effects of negative affectivity, leader-member exchange, and perceived job mobility on in-role and extra-role performance: A Chinese case. Organizational Behavior and Human Decision Processes, 77(1): 3-21.

Hutchings, K., \& Weir, D. 2006. Guanxi and wasta: A comparison. Thunderbird Intemational Business Review, 48(1): 141-156.

Hwang, K.-K. 1987. Face and favor: The Chinese power gamc. American Joumal of Sociology, 92(4): 944-974.

Hwang, K.-K. (黄光国) 2009. Confucian relationalism: Cultural reflection and theoretical construction (儒家光系主义：文化反思与典范重建). Beijing: Beijing University Press. (in Chinese.)

Ibarra, H. 1992. Homophily and differential returns: Sex differences in network structure and access in an advertising firm. Administrative Science Quarterly, 37(3): 422-447.

Ibarra, H. 1997. Paving an alternative route: Gender differences in managerial networks. Social Psychology Quarterly, 60(1): 91-102.

Ip, P. 2009. Is Confucianism good for business ethics in China? Joumal of Business Ethics, 88(3): 463-476.

Jacobs, J. B. 1982. The concept of guanxi and local politics in a rural Chinese cultural setting. In S. L. Greenblatt, R. W. Wilson \& A. A. Wilson (Eds.), Social Interaction in Chinese Society: 209-236. New York: Praeger Publisher.

Jia, L., You, S., \& Du, Y. 2012. Chinese context and theoretical contributions to management and organization research: A three-decade review. Management and Organization Review, $8(1): 173-209$

Jiang, H. (姜翰), \& Jin, Z. (金占明) 2008. An empirical study on the impact of the strength of the relations between enterprises on the mechanism of relationship value. Management World (管理世界), 12: 114-125. (in Chinese.)

Jiang, H. (姜翰),Jin, Z. (金占明), Jiao,J. (焦捷), \& Ma, L. (马力) 2009. Social capital and original sin of entrepreneurial firms in unstable environment. Management World (管理世界), 102-114. (in Chinese.)

Jiang, X., Chen, C. C., \& Shi, K. 2011 . Favor in exchange for trust? The role of subordinates' attribution of supervisory favors. Asia Pacific Journal of Management, DOI 10.1007/ s10490-011-9256-6. 
Khatri, N., Tsang, E. W. K., \& Begley, T. M. 2006. Cronyism: A cross-cultural analysis. Journal of International Business Studies, 37(1): 61-75.

King, A. Y. 1991. Kuan-hsi and network building: A sociological interpretation. Daedalus, 120(2): 63-84.

Kohlberg, L. 1969. Stage and sequence: The cognitive-developmental approach to socialization. In D. A. Goslin (Ed.), Handbook of socialization: Theory and research: $347-480$. Boston, MA: Houghton-Mifflin.

Law, K. S., Wong, C., Wang, D., \& Wang, L. 2000. Effect of supervisor - subordinate guanti on supervisory decisions in China: An empirical investigation. International Joumal of Human Resource Management, 11(4): 751-765.

Li, H., \& Zhang, Y. 2007. The role of managers' political networking and functional experience in new venture performancc: Evidence from China's transition economy. Strategic Management Journal, 28(8): 791-804.

Li, J. J., Poppo, L., \& Zhou, K. Z. 2008. Do managerial ties in China always produce value? Competition, uncertainty, and domestic vs. foreign firms. Strategic Management Journal, 29(4): 383-400.

$\mathrm{Li}$, P. 2008. Toward a geocentric framework of trust: An application to organizational trust. Management and Organization Reviez, 4(3): 413-439.

Li, S. X., Yao, X., Sue-Chan, C., \& Xi, Y. 2011 . Where do social ties come from: Institutional framework and governmental tie distribution among Chinese managers. Management and Organization Reviexe, 7(1): 97-124.

Liang, S., Ling, H., \& Hsieh, S. 2007. The mediating effects of leader-member exchange quality to influence the relationships between paternalistic supervisory and organizational citizenship behaviors. Joumal of American Academy of Business, 10(2): 127-137.

Liang, S. M. (梁漱溟) 1977/1949. The essentials of Chinese culture (中国文化要义). 'Taipei: Wenxuc Publishing House. (in Chinese.)

Liden, R. C., \& Maslyn, J. M. 1998. Multidimensionality of leader-member exchange: An empirical assessment through scale development. Joumal of Management, 24(1): 43-72.

Lin, J., \& Si, S. X. 2010. Can guanxi be a problem? Contexts, ties, and some unfavorable consequences of social capital in China. Asia Pacific Joumal of Management, 27(3): $561-581$.

Lin, N. 1982. Social resources and instrumental action. In P. V. Marsden \& N. Lin (Eds.), Social structure and network analysis: 131-147. Beverly Hills, CA: Sage.

Liu, Y., Li, Y., Tao, L., \& Wang, Y. 2008. Relationship stability, trust and relational risk in marketing channcls: Evidence from China. Industrial Marketing Management, 37(4): $432-446$.

Lovett, S., Simmons, L. C., \& Kali, R. 1999. Guanxi versus the market: Ethics and efficiency.Jourmal of International Business Studies, 30(2): 231-247.

Luk, C.-L., Yau, O. H. M., Sin, L. Y. M., Tse, A. C. B., Chow, R. P. M., \& Lee, J. S. Y. 2008. The effects of social capital and organizational innovativeness in different institutional contexts. Joumal of International Business Studies, 39(4): 589-612.

Luo, D. L. (岁党论), \& Liu, X. L. (刘晓龙) 2009. Political guanxi, entry barrier, and firm performance. Management World (管理世界), 97-106. (in Chinese.)

Luo, J.-D. 2011. Guanxi revisited: An exploratory study of familiar ties in a Chinese workplace. Management and Organization Reviez, 7(2): 329-351.

Luo, X., Griffith, D. A., Liu, S. S., \& Shi, Y. 2004. The effects of customer relationships and social capital on firm performance: A Chinese business illustration. Journal of International Marketing, 12(4): 25-45.

Luo, Y. 1997a. Guanxi: Principles, philosophies, and implications. Human Systems Management, 16(1): 43-51.

Luo, Y. 1997b. Guanxi and performance of foreign-invested enterprises in China: An empirical inquiry. Management International Reviez, 37(1): 51-70.

Luo, Y. 2001. Antecedents and consequences of personal attachment in cross-cultural cooperative ventures. Administrative Science Quarterly, 46(2): 177-201.

Luo, Y. 2003. Industrial dynamics and managerial networking in an emerging market: The case of China. Strategic Management Journal, 24(13): 1315-1327.

Luo, Y. 2008. The changing Chinese culture and business behavior: The perspective of intertwinement between guanxi and corruption. International Business Revieze, 17(2): 188-193. 
Luo, Y., \& Chen, M. 1997. Does guanxi influence firm performance? Asia Pacific Joumal of Management, 14(1): 1-16.

Luo, Y., Huang, Y., \& Wang, S. L. 2012. Guanxi and organizational performance: A meta-analysis. Management and Organization Revieze, 8(1): 139-172.

Luo, Y., Shenkar, O., \& Nyaw, M. 2002. Mitigating liabilities of foreignness: Defensive versus offensive approaches. Journal of International Management, 8(3): 283-300.

Michailova, S., \& Worm, V. 2003. Personal networking in Russia and China: Blat and guanxi. European Management Joumal, 21(4): 509-519.

Moran, P. 2005. Structural vs. relational embeddedness: Social capital and managerial performance. Strategic Management Journal, 26(12): 1129-1151.

Morgan, R. M., \& Hunt, S. D. 1994. The commitment-trust theory of relationship marketing. Joumal of Marketing, 58(3): 20-38.

Morris, M. W., Podolny, J., \& Sullivan, B. N. 2008. Culture and coworker relations: Interpersonal patterns in American, Chinese, German, and Spanish divisions of a global retail bank. Organization Science, 19(4): 517-532.

Nolan, J. 2010. The influence of Western banks on corporate governance in China. Asia Pacific Business Reviere, 16(3): 417-436.

North, D. 1990. Institutions, institutional change and economic performance. Cambridge: Cambridge University Press.

Park, S. H., \& Luo, Y. 2001. Guanxi and organizational dynamics: Organizational networking in Chinese firms. Strategic Management Joumal, 22(5): 455-477.

Parnell, M. F. 2005. Chinese business guanxi: An organization or non-organization? Joumal of Organisational Transformation \& Social Change, 2(1): 29-47.

Parsons, T. 1951. The social system. New York: Free Press.

Peng, M. W., \& Luo, Y. 2000. Managerial tics and firm performance in a transition cconomy: The nature of a micro-macro link. Academy of Management Joumal, 43(3): 486501 .

Peng, S. Q. (彭泗清), \& Yang, C.-F. (杨中芳) 1999. Impact factors and development process of interpersonal relationship. Indigenous Psychological Research (本土心理学研究), 12: 291-312. (in Chinese.)

Peng, Y. 2004. Kinship networks and entrepreneurs in China's transitional economy. American Journal of Sociology, 109(5): 1045-1074.

Pfeffer, J., \& Salancik, G. 1978. The external control of organizations: A resource dependence perspective. New York: Harper \& Row.

Powell, W. W., White, D. R., Koput, K. W., \& Owen-Smith, J. 2005. Network dynamics and ficld evolution: The growth of interorganizational collaboration in the life sciences. American Journal of Sociology, 110(4): 1132-1205.

Provis, C. 2008. Guanxi and conflicts of interest. Journal of Business Ethics, 79(1): 57-68.

Ramasamy, B., Goh, K. W., \& Yeung, M. C. H. 2006. Is guanxi (relationship) a bridge to knowledge transfer? Journal of Business Research, 59(1): 130-139.

Scandura, T. A., \& Graen, G. B. 1984. Moderating effects of initial leader-member exchange status on the effects of a leadership intervention. Joumal of Applied Psychology, 69(3): $428-436$.

Sheer, V. C., \& Chen, L. 2003. Successful Sino-Western business negotiation: Participants' accounts of national and professional cultures. Journal of Business Communication, 40( ( ): $50-85$.

Sheng, S., Zhou, K. Z., \& Li, J.J. 2011 . The effects of business and political ties on firm performance: Evidence from China. Journal of Marketing, 75(1): 1-15.

Shin, S. K., Ishman, M., \& Sanders, G. L. 2007. An empirical investigation of socio-cultural factors of information sharing in China. Information \& Management, 44(2): 165-174.

Song, F., Cadsby, S. B., \& Bi, Y. 2012. Trust, reciprocity, and guanxi in China: An experimental investigation. Management and Organization Revieze, 8(2): 397-421.

Stacey, R. D., Griffin, D., \& Shaw, P. 2000. Complexity and management. New York, NY: Routledge.

Standifird, S. S., \& Marshall, R. S. 2000. The transaction cost advantage of guanxi-based business practices. Journal of World Business, 35(1): 21.

Su, C., \& Littlefield, J. E. 2001. Entering guanxi: A business ethical dilemma in mainland China? Journal of Business Ethics, 33(3): 199-210. 
Su, C., Sirgy, M. J., \& Littlefield, J. E. 2003. Is guanxi orientation bad, ethically speaking? A study of Chinese enterprises. Jourmal of Business Ethics, 44(4): 303-312.

Su, C., Mitchell, R. K., \& Sirgy, M. J. 2007. Enabling guanxi management in China: A hierarchical stakeholder model of effective guanxi. Journal of Business Ethics, 71(3): 301319.

Su, C., Yang, Z., Zhuang, G., Zhou, N., \& Dou, W. 2009. Interpersonal influence as an alternative channel communication behavior in emerging markets: The case of China. Journal of International Business Studies, 40(4): 668-689.

Sue-Chan, C., \& Dasborough, M. T. 2006. The influence of relation-based and rule-based regulations on hiring decisions in the Australian and Hong Kong Chinese cultural contexts. Intemational Journal of Human Resource Management, 17(7): 1267-1292.

Tan, D., \& Snell, R. S. 2002. The third eye: Exploring guanxi and relational morality in the workplacc. Joumal of Business Ethics, 41(4): 361-384.

Tan, J., Yang, J., \& Veliyath, R. 2009. Particularistic and system trust among small and medium enterprises: A comparative study in China's transition economy. Joumal of Business Venturing, 24(6): 544-557.

Tsang, E. W. K. 1998. Can guanxi be a source of sustained competitive advantage for doing business in China? Academy of Management Executive, 12(2): 64-73.

Tsui, A. S., Egan, T. D., \& O'Reilly, C. A. III. 1992. Being different: Relational demography and organizational attachment. Administrative Science Quarterly, 37(4): 549-579.

Tsui, A. S., \& Farh, J.-L. 1997. Where guanxi matters: Relational demography and guanxi in the Chinese context. Work and Occupations, 24(1): 56-79.

Tung, R. L., \& Worm, V. 2001. Network capitalism: The role of human resources in penetrating the China market. International Journal of Human Resource Management, 12(4): $517-534$.

Uzzi, B., \& Spiro, J. 2005. Collaboration and creativity: The small world problem. American Journal of Sociology, $111(2): 447-504$.

Van Buren, H., \& Leana, C. R. 2000. Building relational wealth through employment practices. In C. R. Lcana \& D. M. Rousseau (Eds.), Relational wealth: The advantages of stability in a changing economy: 233-246. New York: Oxford University Press.

Wang, C. L. 2007. Guanxi vs. relationship marketing: Exploring underlying differences. Industrial Marketing Management, 36(1): 81-86.

Wank, D. L. 1999. Commodifying communism: Business, trust, and politics in a Chinese city. New York: Cambridge University Press.

Wank, D. L. 2002. Business-state clientelism in China: Decline or evolution? In T. Gold, D. Guthrie \& D. Wank (Eds.), Social connections in China: Institutions, culture and the changing nature of guanxi: $97-115$. Cambridge, MA: Cambridge University Press.

Warren, D. E., Dunfee, T. W., \& Li, N. 2004. Social exchange in China: The double-edged sword of guanxi. Journal of Business Ethics, 55(4): 355-372.

Wong, P. L.-K., \& Ellis, P. D. 2002. Social ties and partner identification in Sino-Hong Kong international joint ventures. Joumal of International Business Studies, 33(2): 265289.

Wong, Y.-T., Ngo, H.-Y., \& Wong, C. S. 2003. Antecedents and outcomes of employees' trust in Chinesc joint ventures. Asia Pacific Journal of Management, 20(4): 481499.

Wong, Y. H., Leung, T. K. P., Hung, H., \& Ngai, E. W. T. 2007. A model of guanxi development: Flexibility, commitment and capital exchange. Total Quality Management \& Business Excellence, 18(8): 875-887.

Wu, J. F. (旲景 - k), He, D. J. (何大军), Lin, W. (林喡), \& Wang, Y. (王云) 2008. Top managers' political network and firm diversification: A social capital perspective. Management World (管理世界), 107-118. (in Chinese.)

$\mathrm{Wu}, \mathrm{W} . \mathrm{P} .2008$. Dimensions of social capital and firm competitiveness improvement: The mediating role of information sharing. Joumal of Management Studies, 45(1): 122 146.

Xiao, Z., \& Tsui, A. S. 2007. When brokers may not work: The cultural contingency of social capital in Chinese high-tech firms. Administrative Science Quarterly, 52(1): 1-31.

Xin, K., \& Pearce, J. L. 1996. Guanxi: Connections as substitutes for formal institutional support. Academy of Management Joumal, 39(6): 1641-1658. 
Yang, C.-F. (杨中芳) 1999. Conceptualization of interpersonal guanxi and interpersonal affect. Indigenous Psychological Research (本土心理学研究), 12: 105-179. (in Chinese.)

Yang, K.-S. (杨国枢) 1993. Chinese social orientation: A social dynamic perspective. In K.-S. Yang (杨国枢) \& A. P. Yu (余安邦) (Eds.), Chinese psychology and behavior - theory and methodology (中国人的心理与行为: 理念及方法篇): 87-142. Taipei: Kui Kwan Publishing. (in Chinese.)

Yang, M.-H. 2002. The resilience of guanxi and its new deployments: A critique of some new guanxi scholarship. The China Quarterly, 170: 459-476.

Yang, Y. Y. (杨宜音) 2000. 'Zijiren': A case study on Chinese guanxi categorization. Indigenous Psychological Research (本土心理学研究), 13: 277-316. (in Chinese.)

Yau, O. H. M., Lee, J. S. Y., Chow, R. P. M., Sin, L. Y. M., \& Tse, A. C. B. 2000. Relationship marketing the Chinese way. Business Horizons, 43(1): 16-24.

Yi, L. M., \& Ellis, P. D. 2000. Insider-outsider perspectives of guanxi. Business Horizons, 43(1): $25-30$.

Zhang, J., \& Keh, H. T. 2009. Interorganizational exchanges in China: Organizational forms and governance mechanisms. Management and Organization Revieze, 6(I): 123147.

Zhang, N. 2006. Social networks and women's rural-urban migration in contemporary China. Labour, Capital \& Society, 39(2): 104-125.

Zhang, S., \& Li, X. 2008. Managerial ties, firm resources, and performance of cluster firms. Asia Pacific Journal of Management, 25(4): 615-633.

Zhang, X., \& Li, G. 2003. Does guanxi matter to nonfarm employment? Journal of Comparative Economics, 31(2): 315-331.

Zhang, Y., \& Zhang, Z. 2006. Guanxi and organizational dynamics in China: A link between individual and organizational levels. Journal of Business Ethics, 67(4): 375-392.

Zhang, Z.-X. (张志学) 1999. Chinese guanxi perception: A multi-dimensional study. Indigenous Psychological Research (本土心理学研究), 12: 261-288. (in Chinese.)

Zhang, Z.-X., \& Yang, C. F. 1998. Beyond distributive justice: The reasonableness norm in Chinese reward allocation. Asian Joumal of Social Psychology, 1(3): 253-269.

Zhao, H., \& Hsu, C.-C. 2007. Social ties and foreign market entry: An empirical enquiry. Management International Revieze, 47(6): 815-844.

Zhou, X., Li, Q., Zhao, W., \& Cai, H. 2003. Embeddedness and contractual relationships in China's transitional economy. American Sociological Reviewe, 68(1): 75-102.

Zhu, H., Chen, C. C., Li, X. C., \& Zhou, Y. H. 2009. Psychological ownership and the importance of manager-owner relationship in family businesses. Academy of Management Meetings, Montreal, Canada.

Zhuang, G. (庄责军), Li, K. (李珂), \& Cui, X. (崔晓明) 2008. The impact of relationship marketing orientation and interfirm personal guanxi on firms' relational governance in marketing channels. Management World (管理世界), 77-90. (in Chinese.)

Zhuang, G. (庄贵军), \& Xi, Y. (席酉民) 2003. China's cultural basis of relationship marketing. Management World (管理世界), 98-109. (in Chinese.)

Zhuang, G., Xi, Y., \& Tsang, A. S. L. 2010. Power, conflict, and cooperation: The impact of guanxi in Chinese marketing channels. Industrial Marketing Management, 39(1): 137149.

Chao C. Chen (chaochen@business.rutgers.edu), Ph.D. SUNY Buffalo, is a full professor of organization management and global business at Rutgers University, and Visiting Professor at Nanjing University. He has published articles in premier journals of management and organization in areas of Chinese enterprise reform, leadership, rewards allocation preferences, and cross-cultural management. His current research interests include ethical leadership, corporate social responsibility, and cross-cultural research on universalism-particularism. 
Xiao-Ping Chen (xpchen@u.washington.edu) received her Ph.D. from the University of Illinois at Urbana-Champaign. She is currently Professor and Chair of Department of Management and Organization at the Foster School of Business, University of Washington. She is also Editor-in-Chief for Organizational Behavior and Human Decision Processes and Executive Editor for Chinese Management Insights. Her research interests include cooperation and competition in social dilemmas, teamwork and leadership, entrepreneur passion, Chinese guanxi, and cross-cultural communication and management. Shengsheng Huang (huangs@uhv.edu) received his Ph.D. from Rutgers University. He is Assistant Professor of Management at the University of Houston-Victoria. His current research interests include location strategy and technology diffusion of multinational corporations and Chinese-related phenomena such as guanxi, the China automobile industry, and China outward FDI.

Manuscript received: May 13, 2011

Final version accepted: November 13, 2012

Accepted by: Jiing-Lih Larry Farh 